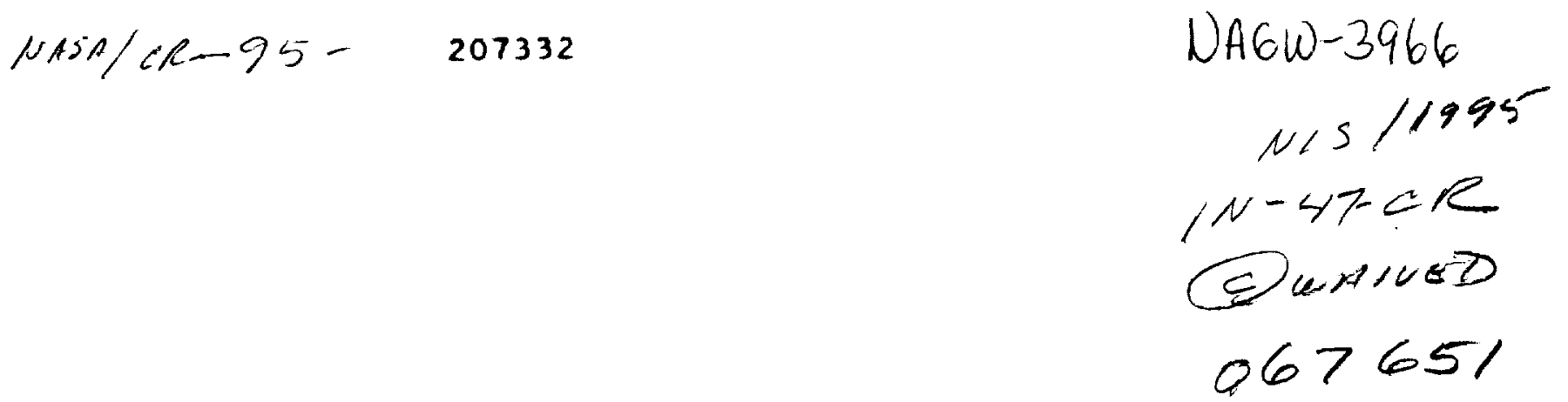

Reprinted from Journal of Climate, Vol. 8. No. 12. December 1995 American Mereorological Society

\title{
Observations of the Global Characteristics and Regional Radiative Effects of Marine Cloud Liquid Water
}

Thomas J. Greenwald and Graeme L. Stephens

SUNDAR A. CHRISTOPHER

THOMAS H. VONDER HAAR 


\title{
Observations of the Global Characteristics and Regional Radiative Effects of Marine Cloud Liquid Water
}

\author{
Thomas J. Greenwald and Graeme L. Stephens \\ Department of Atmospheric Science, Colorado State University, Fort Collins. Colorado \\ SUNDAR A. CHRISTOPHER \\ Institute of Atmospheric Sciences, South Dakota School of Mines and Technology, Rapid City, South Dakota \\ THOMAS H. VONDER HAAR \\ Department of Atmospheric Science, Colorado State University, Fort Collins. Colorado
}

(Manuscript received 16 April 1994, in final form 22 May 1995)

\begin{abstract}
The large-scale spatial distribution and temporal variability of cloud liquid water path (LWP) over the world's oceans and the relationship of cloud LWP to temperature and the radiation budget are investigated using recent satellite measurements from the Special Sensor Microwave/Imager (SSM/I), the Earth Radiation Budget Experiment (ERBE), and the International Satellite Cloud Climatology Project (ISCCP). Observations of cloud liquid water on a $2.5^{\circ} \times 2.5^{\circ}$ grid are used over a 53 -month period beginning July 1987 and ending in December 1991

The highest values of cloud liquid water (greater than $0.13 \mathrm{~kg} \mathrm{~m}^{-2}$ ) occur largely along principal routes of northern midlatitude storms and in areas dominated by tropical convection. The zonally averaged structure is distinctly trimodal, where maxima appear in the midlatinudes and near the equator. The average marine cloud LWP over the globe is estimated to be about $0.113 \mathrm{~kg} \mathrm{~m}^{-2}$. Its highest seasonal variability is typically between $15 \%$ and $25 \%$ of the annual mean but in certain locations can exceed $30 \%$. Comparisons of cloud LWP to temperature for low clouds during JJA and DJF of 1990 show significant positive correlations at colder temperatures and negative correlations at warmer temperatures. The correlations also exhibit strong seasonal and regional variation.

Coincident and collocated observations of cloud LWP from the SSM/I and albedo measurements from the Earth Radiation Budget Satellite (ERBS) and the NOAA-10 satellite are compared for low clouds in the North Pacific and North Atlantic. The observed albedo-LWP relationships correspond reasonably well with theory, where the average cloud effective radius $\left(r_{e}\right)$ is $11.1 \mu \mathrm{m}$ and the standard deviation is $5.2 \mu \mathrm{m}$. The large variability in the inferred values of $r$, suggests that other factors may be important in the albedoLWP relationships. In terms of the effect of the LWP on the net cloud forcing, the authors find that a 0.05 $\mathrm{kg} \mathrm{m}^{-2}$ increase in LWP ( for LWP $<0.2 \mathrm{~kg} \mathrm{~m}^{-2}$ ) results in a $-25 \mathrm{~W} \mathrm{~m}^{-2}$ change in the net cloud forcing at a solar zenith angle of $75^{\circ}$.
\end{abstract}

\section{Introduction}

The importance of cloud liquid water in global climate has been a topic of recent debate. In particular, the cloud-climate feedback mechanism involving cloud liquid water is thought to be potentially significant to the problem of global climate change (Paltridge 1980). Several modeling studies have emphasized the temperature dependence of cloud liquid water as being the driving force behind this feedback (e.g., Charlock

Corresponding author address: Dr. Thomas J. Greenwald, Cooperative Institute for Research in the Atmosphere, Colorado State University, Foothills Campus, Fort Collins, CO 80523.

E-mail: green @ taurus.cira.colostate.edu
1982; Somerville and Remer 1984; Betts and Harshvardhan 1987). Some of these studies used in situ measurements of cloud liquid water over limited continental regions to conclude that cloud liquid water might provide a relatively large negative feedback on climate. However, the latest modeling efforts using general circulation models (GCMs) (e.g., Taylor and Ghan 1992) suggest that the cloud liquid water feedback may be more neutral since cloud longwave radiative effects tend to compensate for the increased albedos. Also, Twomey (1991) has raised doubts about whether a strong dependence of liquid water content on temperature actually exists, following a reinterpretation of the in situ measurements. Furthermore, even if the adiabatic liquid water content were to increase with temperature, there is no assurance that the clouds would 
possess greater liquid water in a warmer atmosphere since other, nonadiabatic, microphysical processes might offset the adiabatic increase in liquid water, such as increased precipitation efficiency (Twomey 1991). Other evidence contrary to the idea that cloud liquid water generally increases with temperature comes from recent satellite measurements of cloud optical depth from Tselioudis et al. (1992), which demonstrate that optical depth and temperature are anticorrelated over most areas of the globe.

Cloud feedback processes in general have been identified as one of several components of the climate system that must be understood before we can reliably predict climate change. Unfortunately, there are presently large gaps in our knowledge about such fundamental questions as, What is the global distribution of cloud liquid water and ice water? What are the main physical processes that determine their distribution? and even more importantly, What are their respective radiative effects? Of course one of the major reasons for these deficiencies is that global observations of cloud properties have only recently become available. In an effort to address these and other related issues, the Global Energy and Water cycle Experiment (GEWEX) has proposed strategies to monitor cloud water and other cloud properties on a global scale.

A full understanding of the cloud liquid water feedback and to what extent it will ultimately affect climate and climate change will perhaps be possible only through the use of GCMs. Nevertheless, observations can play a key role in improving our understanding of the factors that govern cloud liquid water and also provide descriptions of the interactions of cloud liquid water with other variables of the climate system. These descriptions can also serve as sources of parameterization for simple climate models or as tests for the new generation of GCMs that explicitly include the prediction of cloud liquid water.

Observations of cloud liquid water from satellitebased systems have been restricted almost exclusively to total column estimates using optical (e.g., Lin and Rossow 1994) and passive microwave methods (e.g., Petty 1990; Greenwald et al. 1993). Despite their limitations these types of measurements can be extremely useful in understanding the horizontal distribution of cloud liquid water [information about the detailed vertical structure of cloud liquid water from satellite measurements may be possible in the future using cloud profilers, such as the $94-$ GHz radar proposed for TRMM-2 (Tropical Rainfall Measuring Mission)]. The chief weaknesses of the optical methods include the effects of ice clouds and multilevel clouds and the nonlinearities arising from cloud brokenness/inhomogeneities within the field of view (FOV) of the instrument. The microwave techniques by comparison represent a more direct approach but are less accurate in areas of precipitating cloud systems, involve relatively coarse resolution measurements, and are usually restricted to water surfaces, though retrievals may be possible over land when combined with IR measurements (Jones and Vonder Haar 1990). With the emergence of new spaceborne microwave instruments of improved calibration and high stability, such as the Special Sensor Microwave/Imager (SSM/I), it has become possible to monitor successfully cloud liquid water on a global scale since July of 1987.

This study presents a multiyear survey of cloud liquid water over the oceans and examines the relationships of this bulk cloud property to atmospheric temperature and the Earth's radiation budget using observations from the $S S M / I$, the International Satellite Cloud Climatology Project (ISCCP; e.g., Rossow and Schiffer 1991), and the Earth Radiation Budget Experiment (ERBE; e.g., Barkstrom 1984). Our primary aim is to address some of the scientific concerns outlined by GEWEX. These include describing the spatial distribution and temporal statistics of cloud liquid water and also providing insight into the factors that shape its distribution. Moreover, we wish to determine the coupling of cloud liquid water to the temperature field and the radiation budget in order to provide important clues as to the role of cloud liquid water in global climate.

A similar temperature sensitivity analysis was conducted by Tselioudis et al. (1992) using observations of cloud optical depth. Assuming that variations of optical depth are primarily due to changes in liquid water path, the results of Tselioudis et al. can be used to infer the relationship of cloud liquid water to temperature. The advantages of this study in determining this relationship are the use of measurements of cloud liquid water and the elimination of possible effects from ice clouds at middle and high latitudes during the winter. In addition, this study differs from earlier comparisons of liquid water and the radiation budget, such as by Stephens and Greenwald (1991), in that we collocate instantaneous measurements of cloud liquid water and the radiation budget and focus only on low-level clouds.

The first part of this paper gives a description of the cloud liquid water datasets and includes an estimate of their expected errors. We also explain some of the shortcomings of these types of datasets. In section 3 we describe the spatial and temporal characteristics of cloud liquid water across the world's oceans over a 53-month period. Section 4 deals with the global, regional, and seasonal aspects of the relationship of cloud liquid water to temperature. In section 5 we explore the relationships of cloud liquid water to albedo and compare these observed relationships to theory in selected regions. In addition, we investigate the effect of cloud liquid water on the net cloud forcing. Finally, in section 6 we present the important conclusions of this work. 


\section{Cloud liquid water data}

The cloud liquid water datasets are derived from SSM/I measurements on the Defense Meteorological Satellite Program (DMSP) F-8 satellite over a nearly continuous period from 9 July 1987 to 31 December 1991 (the entire month of December 1987 is missing due to a shutdown of the instrument). The SSM/I is a seven-channel polarimetric radiometer that detects radiation at $19.35,22.235,37$, and $85.5 \mathrm{GHz}$ (see Hollinger et al. 1990 for a detailed description of the SSM/ I). The datasets used in section 3 of this study consist of monthly mean quantities on a $2.5^{\circ} \times 2.5^{\circ}$ grid.

The physical model used to retrieve vertically integrated cloud liquid water simultaneously with water vapor over water surfaces is a modified form of the method outlined by Greenwald et al. (1993). This technique is analogous to the physical methods used in the retrieval of water vapor and liquid water from groundbased microwave radiometers (see, e.g., Westwater 1978). The present model is also conceptually similar to the physical models used, for example, by Wentz (1983) and Petty and Katsaros (1992).

An improved analytic form for the upwelling vertical (v) or horizontal ( $h$ ) polarization brightness temperatures at the top of the atmosphere, based on a reworking of the results of Tjemkes et al. (1991), can be expressed at frequency $\nu$ as

$$
\begin{aligned}
T_{v / h, \nu}= & T_{s}\left[1-\left(1-\epsilon_{v / h, \nu}\right) \mathscr{J}_{\nu}^{2}\right]-\Gamma\left[Z_{\nu}^{+}\right. \\
& \left.+\left(1-\epsilon_{v / h, \nu}\right) Z_{\nu}^{-} \mathscr{J}_{\nu}\right]+T_{\cos }\left(1-\epsilon_{v / h, \nu}\right) \mathscr{I}_{\nu}^{2},
\end{aligned}
$$

where

$$
\begin{gathered}
Z_{\nu}^{+}=\frac{1}{\mu}\left(\mathscr{J}_{o x, \nu} H_{w} \tau_{w, \nu}+H_{l} \tau_{l, \nu} \mathscr{J}_{l, \nu}\right) \\
Z_{\nu}^{-}=\frac{\mathscr{J}_{\nu}}{\mu}\left[\mathscr{J}_{o x, \nu} H_{w}\left(\tau_{w, \nu}+c \tau_{w, \nu}^{2} / \mu\right)+H_{l} \tau_{l, \nu} \mathscr{J}_{l, \nu}\right]
\end{gathered}
$$

are the atmospheric terms, $T_{s}$ is the surface skin temperature, $\mu$ is the cosine of the viewing angle, $\epsilon_{v / h, \nu}$ is the surface emissivity at v- or h-polarization, $\mathscr{J}_{\nu}$ is the total transmission of the atmosphere $\left(\mathscr{J}_{w, \nu} \mathscr{J}_{l, \nu} \mathscr{J}_{o x, \nu}\right), \tau_{w, \nu}$ is the water vapor optical depth (defined as the water vapor mass absorption coefficient, $\kappa_{w, \nu}$, times the integrated water vapor), $\Gamma$ is the temperature lapse rate, $H_{w}$ is the water vapor scale height, and $T_{\text {cos }}$ is the cosmic background temperature. The transmission terms for water vapor, oxygen, and liquid water are defined, respectively, as $\mathscr{I}_{w, \nu}=\exp \left(-\tau_{w, \nu} / \mu\right), \mathscr{I}_{o x, \nu}=\exp \left(-\tau_{o x, \nu} /\right.$ $\mu$ ) and $\mathscr{J}_{l, \nu}=\exp \left(-\tau_{l, \nu} / \mu\right)$, where $\tau_{l, \nu}$ is the liquid water optical depth (defined as the liquid water mass absorption coefficient, $\kappa_{t, \nu}$, times the integrated liquid water) and $\tau_{o x, \nu}$ is the oxygen optical depth. The contribution from the effective height of the liquid water is included in (2) and (3) by assuming that the cloud is a delta function, whereby the liquid water is concentrated at a height $H_{l}$. The contribution from the cosmic background, although very small, is included as the last term in ( 1 ). Finally, the quantity $c \tau_{w, \nu}^{2} / \mu$ is a secondorder term in the expansion of $Z_{\nu}^{-}$that was required as a result of discrepancies of the analytic expression with more detailed calculations of $T_{\nu, \nu}$. The expansion yields a value for $c$ of 0.25 ; however, a much larger value of 3.2 was found to provide the best agreement. This value was used for the three lowest frequencies, but is only important at $22.235 \mathrm{GHz}$.

One simplification in (1) is that the downwelling radiation is always specularly reflected by the sea surface, even when the surface becomes rough. This assumption is likely to be violated under windy conditions and particularly for the h-polarization component of the reflected sky radiation. Several investigators have attempted to estimate and account for the nonspecular behavior of the reflected sky radiation (e.g., Wentz 1983; Petty and Katsaros 1994). 'This effect, however, is less important for the v-polarization component, but could be incorporated into the present model if needed. Another simplification is that the surface air temperature $\left(T_{a}\right)$ is set equal to $T_{s}$. The expression in (1) could be easily generalized to include $T_{a}$.

Using measurements at two different frequencies, the integrated water vapor $(W)$ and cloud liquid water (L) can be derived iteratively from Eqs. (1)-(3). Specification of the unknown variables and a detailed account of the retrieval procedure are outlined in the appendix. The v-polarization channels are used as opposed to the h-polarization channels since they are much less sensitive to sea surface roughness effects for viewing angles typical of the SSM/I (i.e., $\approx 53^{\circ}$ ). A combination of measurements at $19.35 \mathrm{v}$ and $37 \mathrm{v} \mathrm{GHz}$ is used for the liquid water retrievals since it results in lower variability in clear regions and compares better against surface observations than for the $22.235 \mathrm{v}$ and $37 \mathrm{v} \mathrm{GHz}$ pair. Measurements at $85.5 \mathrm{GHz}$ would provide greater sensitivity to changes in cloud liquid water for lower liquid water and water vapor amounts. We did not take advantage of these measurements since, unfortunately, both channels failed during the 53month period of interest. In future work it will be straightforward to include measurements at $85.5 \mathrm{GHz}$ as well in the retrieval model.

Estimates of the retrieval errors are derived from two different sources. First, using a limited set of groundbased microwave measurements of liquid water from the study of Greenwald et al. (1993), the retrievals are found to have an mins difference of $0.040 \mathrm{~kg} \mathrm{~m}^{-2}$ over San Nicolas Island and the North Sea. Second, an error analysis for nonprecipitating clouds, similar to the one presented by Greenwald et al. (1993), shows the retrievals have errors of roughly $30 \%$ on average but which vary depending primarily on the atmospheric conditions and the amount of liquid water. The water vapor retrievals, on the other hand, have estimated errors of about $5 \mathrm{~kg} \mathrm{~m}^{-2}$ for both the $19 \mathrm{v} / 37 \mathrm{v}$ and com- 
bined $19 \mathrm{v} / 22 \mathrm{v} / 37 \mathrm{v}$ methods based on an extensive comparison with radiosonde observations by Jackson and Stephens (1995).

The major limitation of the cloud liquid water path (LWP) datasets presented in this paper, as with all microwave-derived cloud LWP datasets, is the large uncertainties of the estimates in regions of rainfall. When the present method (based on $37 \mathrm{GHz}$ ) is applied to measurements that have significant rainfall within the sensor's FOV, the retrievals will in most cases overestimate the actual cloud LWP, mainly as a result of increased absorption/emission by raindrops. ${ }^{1}$ Because of this limitation, a simple liquid water threshold is applied to discriminate between "precipitating" and "nonprecipitating" FOVs, such as done by Greenwald et al. (1993). If the retrieved liquid water exceeds 0.4 $\mathrm{kg} \mathrm{m}^{-2}$, then it is flagged as possible precipitation and excluded from the analysis. Although we are confident that most retrievals suspected of being greatly contaminated by precipitation have been eliminated, an independent method of detecting precipitation (which possibly takes advantage of multiple frequencies) may be more desirable in future studies. One must bear in mind that these datasets will inevitably contain low biases in areas of precipitation because they exclude cloud liquid water in precipitating cloud systems.

When producing cloud LWP datasets for climate studies, it is a common and simple practice to include all satellite retrievals in the averaging process, whether or not the FOVs are clear or cloudy. As pointed out by Lin and Rossow (1994), this type of averaging does not, strictly speaking, yield the mean cloud liquid water since FOVs that are free of water clouds are also included. In their analysis, Lin and Rossow used noncoincident (within $1.5 \mathrm{~h}$ ) $\mathbb{R}$ data to aid in screening out clear FOVs.

How one averages the LWP data depends on the application that is of interest to the scientist. For example, when comparing observations to cloud liquid water fields generated by GCMs, one might want to include clear FOVs in the average. However, if one is specifically interested in cloud properties, then it might be better to exclude clear FOVs. Thus, it is highly recommended that both types of datasets be produced.

Unless specifically mentioned, the cloud LWP results presented in this study include only cloudy FOVs. Since for our purposes it would be clearly impractical, given the volume of data, to use IR data to aid in identifying clear FOVs, we use instead a liquid water threshold. This is similar to the scene identification approach of Bauer and Schluessel (1993), who used liquid water retrievals below $0.05 \mathrm{~kg} \mathrm{~m}^{-2}$ as an indicator of clear FOVs. Here, we use a threshold of 0.048

\footnotetext{
'This is ignoring. of course, the separate issue of beam filling, which leads to underestimates of the cloud LWP.
}

$\mathrm{kg} \mathrm{m}^{-2}$, which is three times the standard deviation of the retrievals from the clear sky dataset described by Greenwald et al. (1993).

This threshold was selected for two reasons. First, it covers nearly the entire spread of the clear sky retrievals. Second, monthly mean values of cloud amount derived from the liquid water data using this threshold are reasonably consistent with ISCCP cloudiness data. The threshold works well under most conditions, except in regions of rough seas and low water vapor as determined from comparisons of the liquid water variability within $1^{\circ} \times 1^{\circ}$ grid boxes. Thus, for $W<12 \mathrm{~kg} \mathrm{~m}^{-2}$ and $u>8 \mathrm{~m} \mathrm{~s}^{-1}$, where $u$ is the retrieved near-surface wind speed, the threshold is set to $0.024 \mathrm{~kg} \mathrm{~m}^{-2}$.

The major disadvantage in using a liquid water threshold is that the results will, to a certain extent, depend on the chosen threshold ( $\mathrm{Lin}$ and Rossow 1994). To test the sensitivity of the results to different thresholds, we compared monthly mean quantities of cloud LWP computed at the threshold pairs of 0.048 / $0.024 \mathrm{~kg} \mathrm{~m}^{-2}$ and $0.032 / 0.016 \mathrm{~kg} \mathrm{~m}^{-2}$. The latter threshold pair was chosen as an approximate lower limit since smaller thresholds yielded unrealistically high monthly mean cloud amounts. We find that the differences in the results between these sets of thresholds varied greatly depending on the cloudiness conditions. As expected, the smallest differences occurred in highly cloudy areas ( $>80 \%$ cloudiness), being less than $10 \%$. In areas of $50 \%$ cloudiness the differences ranged from about $10 \%$ to $20 \%$, whereas for the lowest cloudiness $(<30 \%)$ the differences were the greatest, sometimes as large as $30 \%$.

Despite the difficulties in identifying cloudy SSM/I FOVs using only a liquid water threshold, the results presented in the following section can still provide useful information as long as it is recognized that the largest uncertainties $(\approx 30 \%)$ occur generally in those regions with the lowest cloudiness. Obviously, there is a need for an independent method of detecting cloudy SSM/I FOVs and, even more importantly, determining the degree of cloudiness within the sensor's FOV. One possible candidate is visible and IR measurements from the Operational Line Scanner (OLS) on the DMSP satellites, which might be useful in the future processing of cloud liquid water datasets.

\section{Spatial distribution and temporal variation of cloud liquid water}

Figure 1 shows the mean SSM/I cloud LWP for the 53 monthly averages. This figure suggests that the horizontal distribution of cloud LWP is in many ways tied to large-scale dynamical patterns. For example, an indication of the path of northern midlatitude storms can be observed, where the liquid water is often greater than $0.125 \mathrm{~kg} \mathrm{~m}^{-2}$. Also, the signatures of the intertropical convergence zone (ITCZ) are evident in the Pacific and Atlantic, and high LWPs of over 0.125 


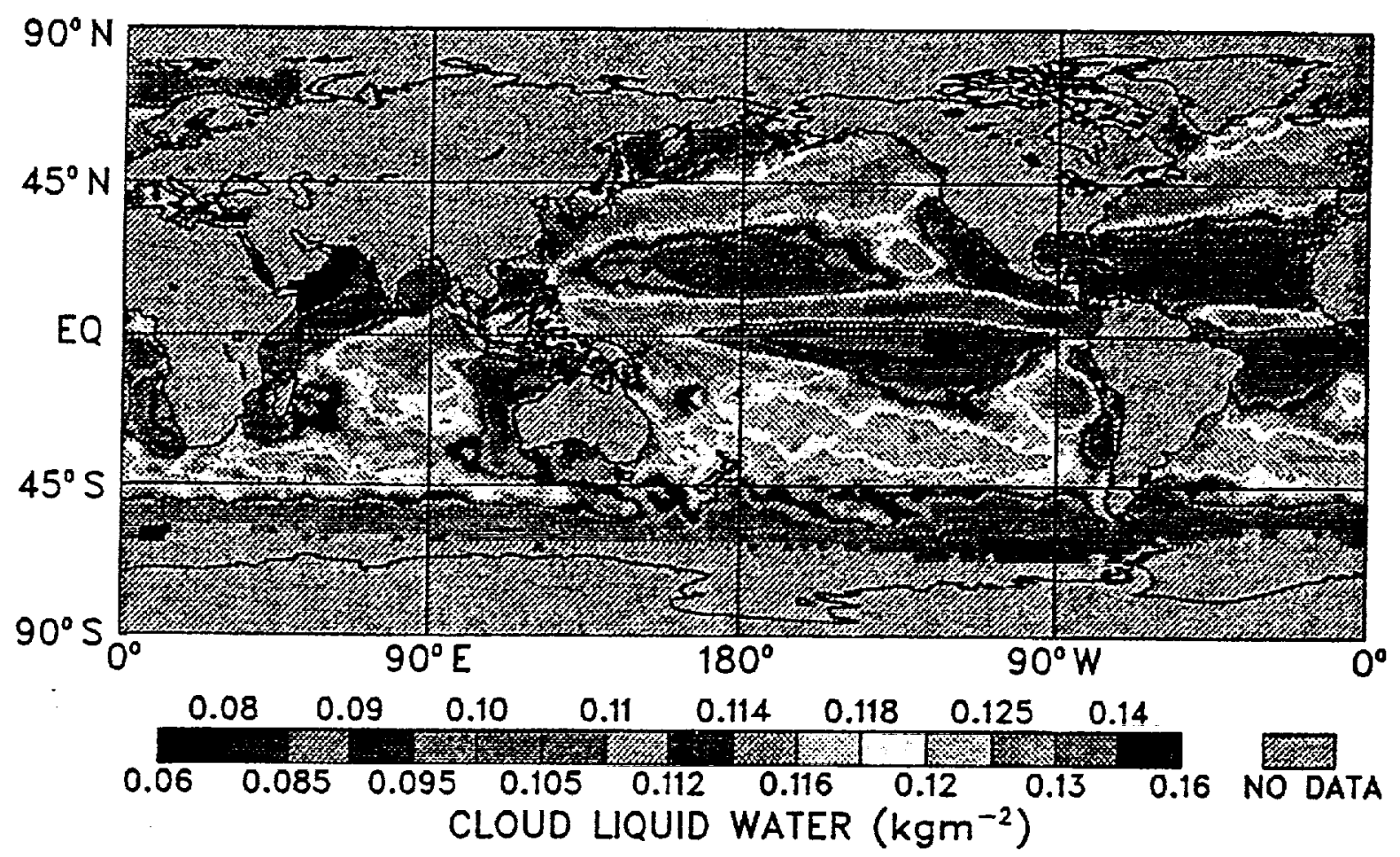

FiG. 1. Global distribution of the mean cloud liquid water path $\left(\mathrm{kg} \mathrm{m}^{-2}\right)$ over the oceans derived from the SSM/I and averaged from July 1987 to December 1991 on a $2.5^{\circ} \times 2.5^{\circ}$ grid. Gray areas denote regions of land or sea ice.

$\mathrm{kg} \mathrm{m}^{-2}$ are common in the Indonesian area and in the eastern tropical Indian Ocean.

In other regions of interest, the South Pacific convergence zone (SPCZ) is well represented by a relative maximum, and there is a hint of the Southern Hemisphere storm track in the southern Indian Ocean. In

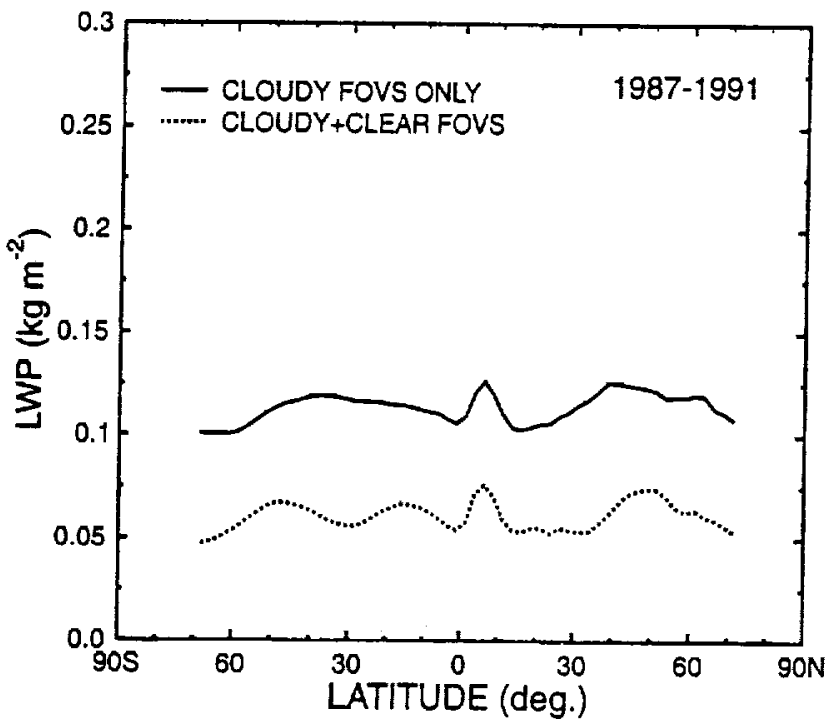

Fic. 2. Zonal average liquid water path $\left(\mathrm{kg} \mathrm{m}^{-2}\right)$ averaged from July 1987 to December 199 I. Solid curve includes only cloudy fields of views (FOVs) in the average, while dotted curve includes cloudy and clear FOVs in the average. areas typically dominated by subtropical highs and subsidence, the cloud LWP is generally lower except in those regions off the west coasts of the major continents, particularly near North and South America, where extensive and persistent stratocumulus reside. The lowest liquid water (less than $0.09 \mathrm{~kg} \mathrm{~m}^{-2}$ ) is associated with areas of subsidence and generally concentrated near land masses except perhaps in the central Pacific.

The zonal average characteristics of the mean cloud LWP are shown in Fig. 2. These calculations do not reflect the fact that there is more ocean relative to land in the southern oceans than for the northern oceans. As a result, features in the Northern Hemisphere will be slightly emphasized. The zonal profile, as seen by the solid curve, is represented as three distinct peaks. The maxima in the midlatitudes are likely a result of the cloudiness associated with baroclinic storm systems. The maximum at about $5^{\circ} \mathrm{N}$ is caused mainly by the ITCZ in the eastem Pacific. Regions of minima are located in the subtropics. There is also an overall decline in the cloud LWP as one approaches the highest latitudes. The global average (weighted by area) is 0.113 $\mathrm{kg} \mathrm{m}^{-2}$.

Also depicted in Fig. 2 for comparison is the 53month mean LWP that also includes clear satellite FOVs. If a given FOV was determined to be clear, then the retrieval was set to zero to reflect the fact that no liquid water should be present. The differences between these two methods of averaging is dramatic in 
both magnitude and latitudinal shape. The "cloudyclear" dataset is often nearly a factor of 2 smaller than the "cloudy" dataset and has four, as opposed to three, distinct maxima. The global average for these data is $0.0608 \mathrm{~kg} \mathrm{~m}^{-2}$.

The seasonal character of the spatial distribution of cloud LWP is shown in Figs. 3 and 4. A distinct maximum, which roughly coincides with the principal track of cyclones (see, e.g., Wallace et al. 1988), is clearly visible over the northern oceans during the DJF, MAM, and SON seasons. The large production of cloud liquid water mass off the east coasts of China and the United States, especially during DJF and MAM, is due to the significant fluxes of latent and sensible heat and subsequent convective instabilities that occur as a result of the advection of cold, dry continental air over the warmer ocean.

One of the most striking features in the seasonal maps is the broad region of high cloud LWP (from 0.13 $\mathrm{kg} \mathrm{m}^{-2}$ to more than $0.15 \mathrm{~kg} \mathrm{~m}^{-2}$ ) during JJA in the North Pacific and Atlantic in Fig. 3. The conditions responsible for the formation of cloud liquid water during the summer in this region are vastly different than in other seasons. At this time of the year there is diminished storm activity and a far greater occurrence of stratus clouds. The specific cause of the increased stratus cloudiness is not well understood; however, Klein and Hartmann (1993) have shown that the cloudiness is well correlated with the presence of low-level temperature inversions and high stability in the lower troposphere.

To investigate further the relationship between cloud LWP and cloudiness, we show in Fig. 5 a plot of monthly mean LWP (using the cloudy-clear datasets) versus total cloud amount derived from ISCCP for the summer months from July 1987 to June 1991 over the North Pacific $\left(50^{\circ}-35^{\circ} \mathrm{N} ; 155^{\circ}-125^{\circ} \mathrm{W}\right)$. Each data point represents a $2.5^{\circ} \times 2.5^{\circ}$ grid box average. The relationship between these quantities is shown to be reasonably well defined and nonlinear. These results support the idea that the increase in the liquid water is likely attributed, in large part, to greater cloudiness. However, we cannot rule out that some of the observed increase in cloud liquid water may also be caused by an enhanced thickness of the clouds.

Another distinguishing phenomenon in the seasonal maps is the zonal shift of the maximum cloud LWP along the ITCZ. While the absolute liquid water estimates along the ITCZ are likely to be dubious, the relative changes from one season to another may be fairly realistic. The most salient feature in the eastern Pacific is the movement of the LWP maximum to the west during the MAM season in Fig. 4. This result is consistent with similar shifts in rainfall maxima that were seen from the climatic rainfall data observed by Spencer (1993) based on measurements from the Microwave Sounding Unit (MSU) on the NOAA satellites.
Aside from the obvious maximum of the ITCZ, other prominent characteristics in the Tropics can be seen for JJA in Fig. 3. For example, evidence of the southern Asian monsoon is observed as liquid water maxima exceeding $0.13 \mathrm{~kg} \mathrm{~m}^{-2}$ on the western side of India and along the coast of Burma. In contrast, the cloud LWP is a minimum (less than $0.085 \mathrm{~kg} \mathrm{~m}^{-2}$ ) in this same region during DJF, which is attributed to the reversal of the monsoonal flow and a dominance of the descending branch of the Hadley circulation. There is also an indication of a cloud LWP maximum in the West Pacific where the convection is known to be most vigorous. During DJF when the greatest convective activity advances to the southern parts of Indonesia and just north of Australia, the LWP values are greater than 0.13 $\mathrm{kg} \mathrm{m}^{-2}$. We should stress that the magnitude of the cloud LWPs in these regions should be treated with some suspicion since the retrievals are less reliable where precipitating cloud systems prevail.

The variation of cloud LWP with season in terms of zonal-mean profiles are shown in Fig. 6. All seasons retain, for the most part, a basic trimodal structure as seen earlier for the 53-month mean. In both hemispheres, particularly in the north, the equatorward push of cloud liquid water during the winter is observed. It is not clear, however, whether the seasonal differences in the midlatitudes are strictly a consequence of dynamical influences. The conversion of liquid water to ice water may also be partly responsible for the lower liquid water values during the winter season. The ITCZ shows little seasonal variation in its position and remains confined to the Northern Hemisphere. Evidence of the summertime convection in the Southern Hemisphere Tropics can also be seen as a relative maximum during DJF near $10^{\circ} \mathrm{S}$.

Further information about the temporal variation of cloud LWP can be gathered by calculating the sample interannual and intra-annual standard deviations, which for this study are defined, respectively, at each gridbox as

$$
\begin{gathered}
\sigma_{\text {inter }}=\frac{1}{12} \sum_{j=1}^{12}\left[\frac{1}{N-1} \sum_{i=1}^{N}\left(L_{i j}-\overline{L_{j}}\right)^{2}\right]^{1 / 2} \\
\sigma_{\text {intra }}=\left[\frac{1}{52} \sum_{k=1}^{5.3}\left(L_{k}-\bar{L}\right)^{2}\right]^{1 / 2}
\end{gathered}
$$

where $N$ is 4 or 5 years depending on the month, $\bar{L}_{j}$ is the average observation over $N$ years for a month of the year $j$, and $\bar{L}$ is the average observation over all 53 months.

Calculations of $\sigma_{\text {inter }}$ and $\sigma_{\text {intra }}$ are shown as global distributions in Fig. 7a and $7 \mathrm{~b}$, respectively. Regions of the highest interannual variation in Fig. 7a of over $0.02 \mathrm{~kg} \mathrm{~m}^{-2}$ occur off the western coast of Africa near Cape Verde, off the northwest coast of Australia, near Argentina, and along the equator in the mid-Pacific. Other relative maxima are evident, for example, in the 
(a)

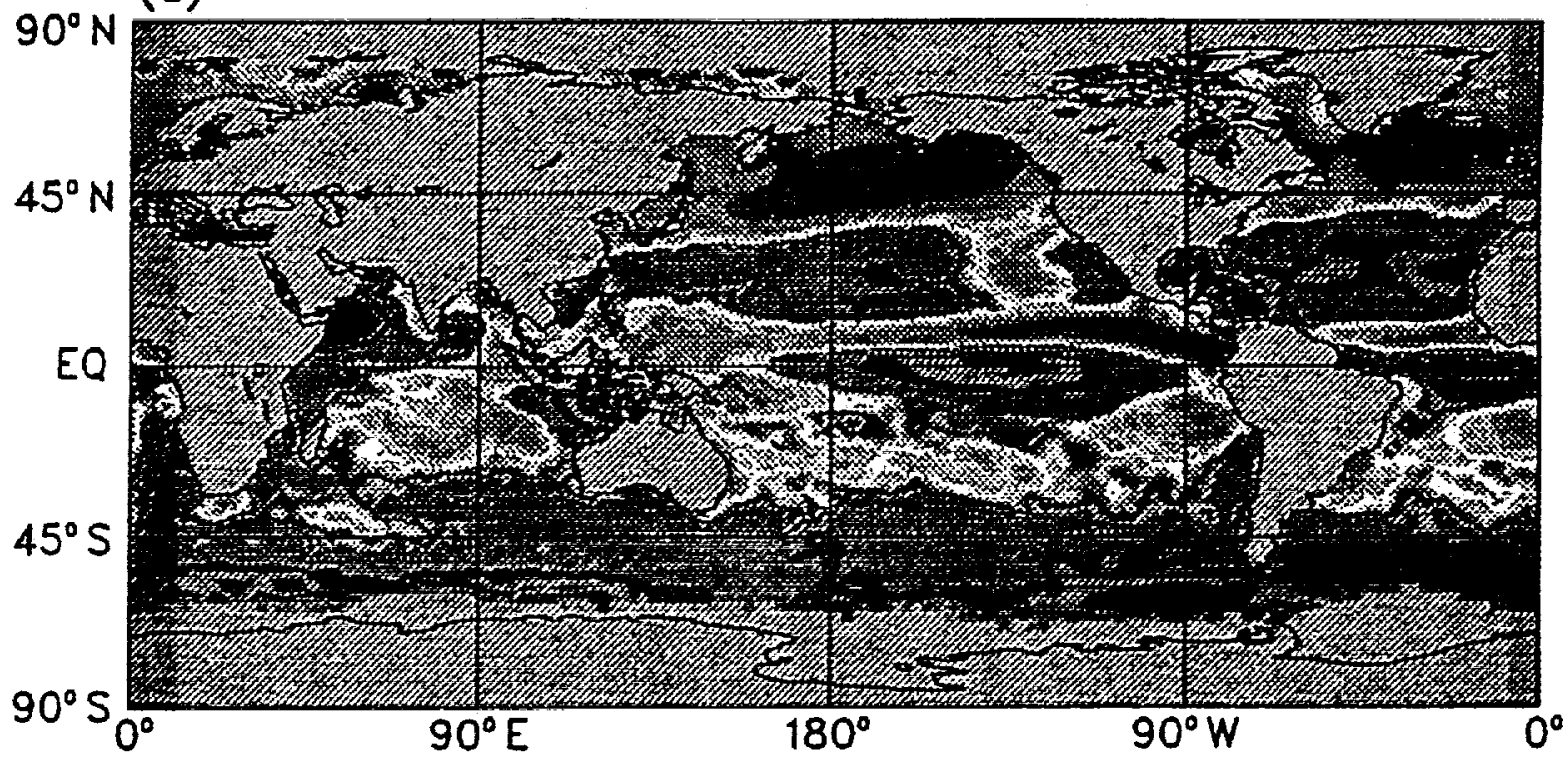

(b)

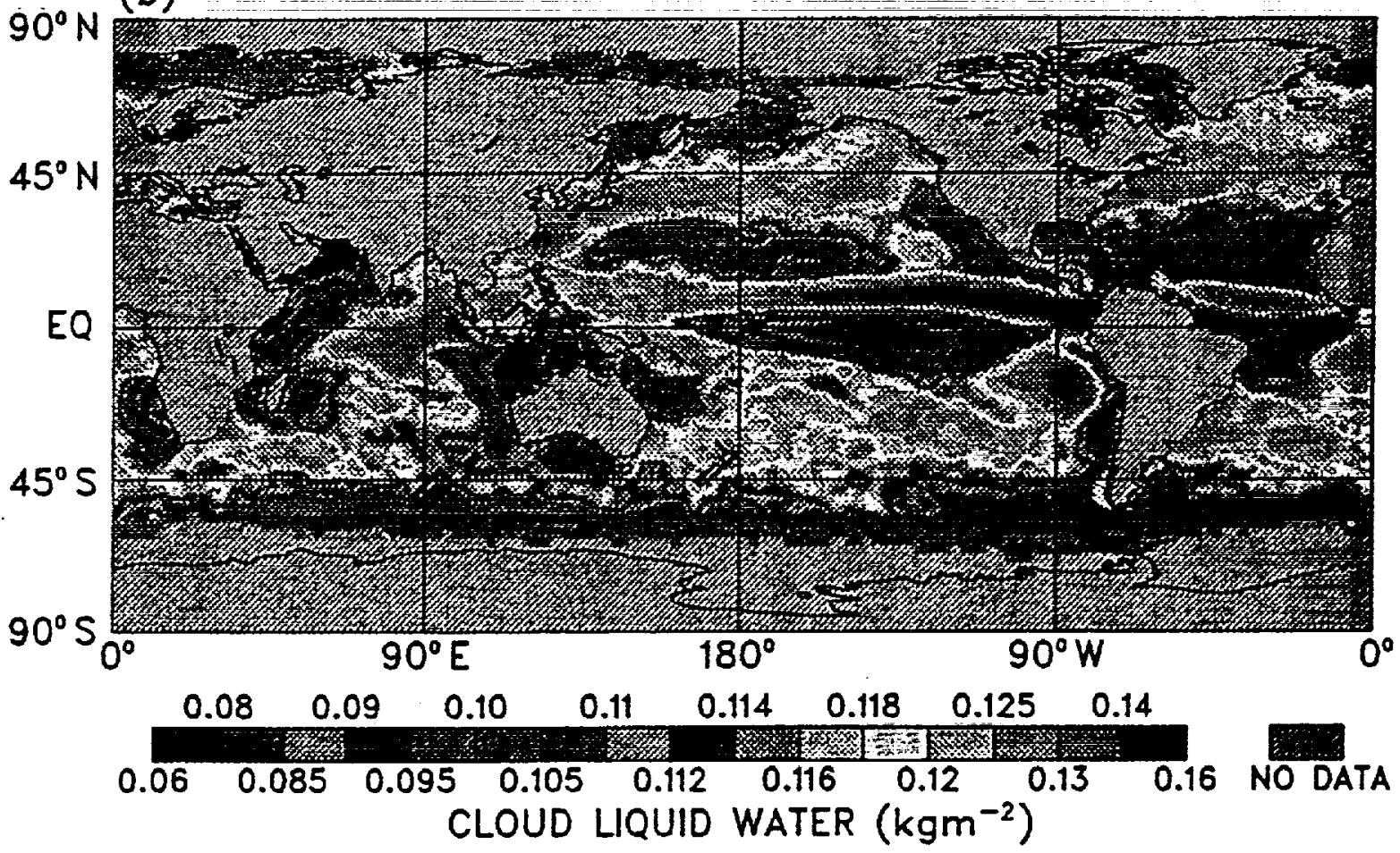

FIc. 3. Global distributions of cloud liquid water path $\left(\mathrm{kg} \mathrm{m}^{-3}\right)$ over the ocean derived from the SSM/I for (a) JJA and (b) SON.

Gulf of Mexico and in the Mediterranean Sea. Minimal year to year variability (less than $0.01 \mathrm{~kg} \mathrm{~m}^{-2}$ ) is seen in areas where high pressure systems commonly occur and throughout the midlatitude southern oceans. In certain locations, such as near the northwest Australian coast and near Cape Verde, the interannual variations can often reach $25 \%$ of the annual mean. Typically, however, these variations are about $10 \%$ of the annual mean.
The intra-annual variability shown in Fig. $7 \mathrm{~b}$, in many ways, resembles the interannual variability, but there are important differences. For instance, areas of high variability (as large as $0.027 \mathrm{~kg} \mathrm{~m}^{-2}$ ) exist in the tropical Atlantic, which is a result of the significant meridional excursions of the ITCZ. There are also large seasonal changes in the far eastern Pacific ITCZ. The Asian and Australian monsoons are exhibited as 
(a)

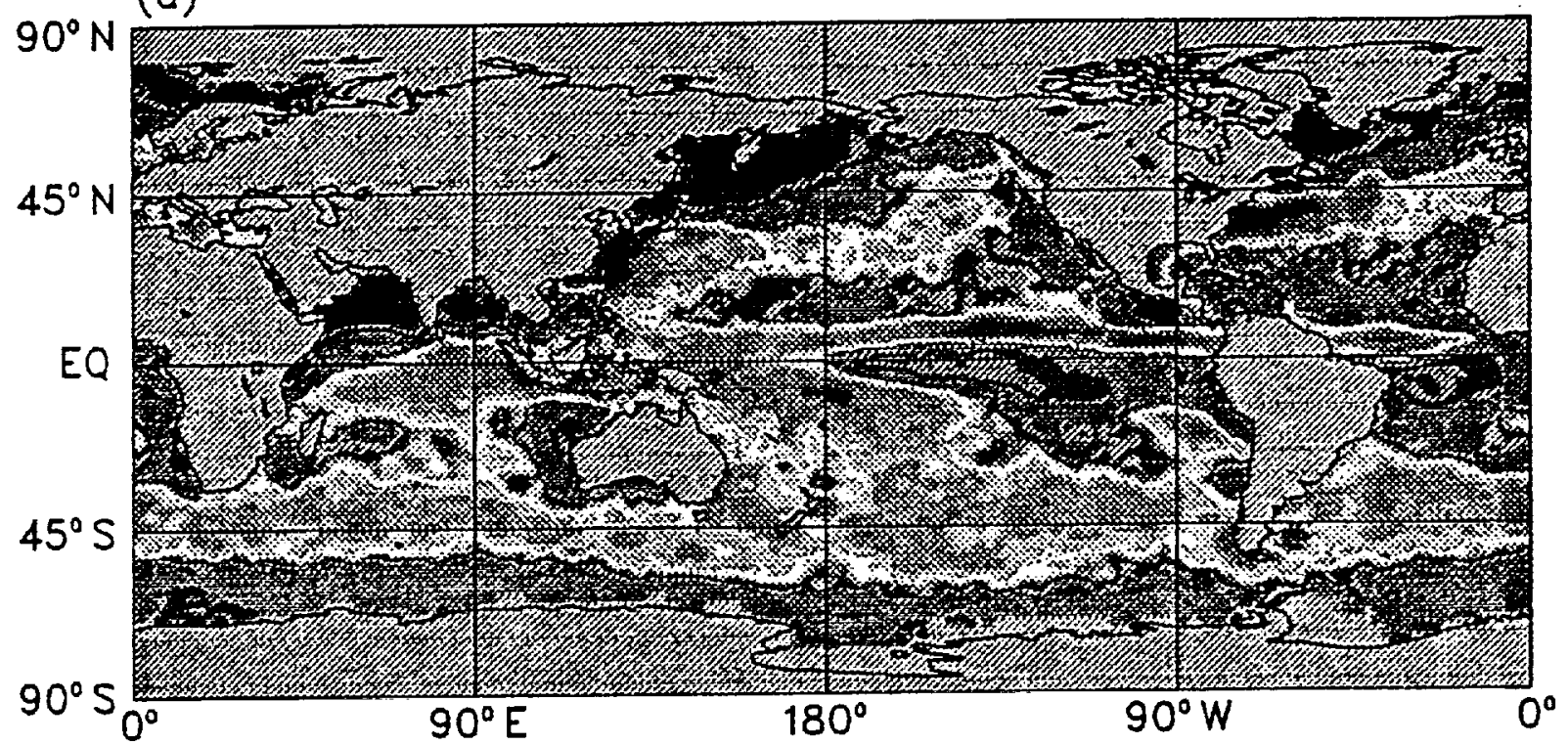

(b)

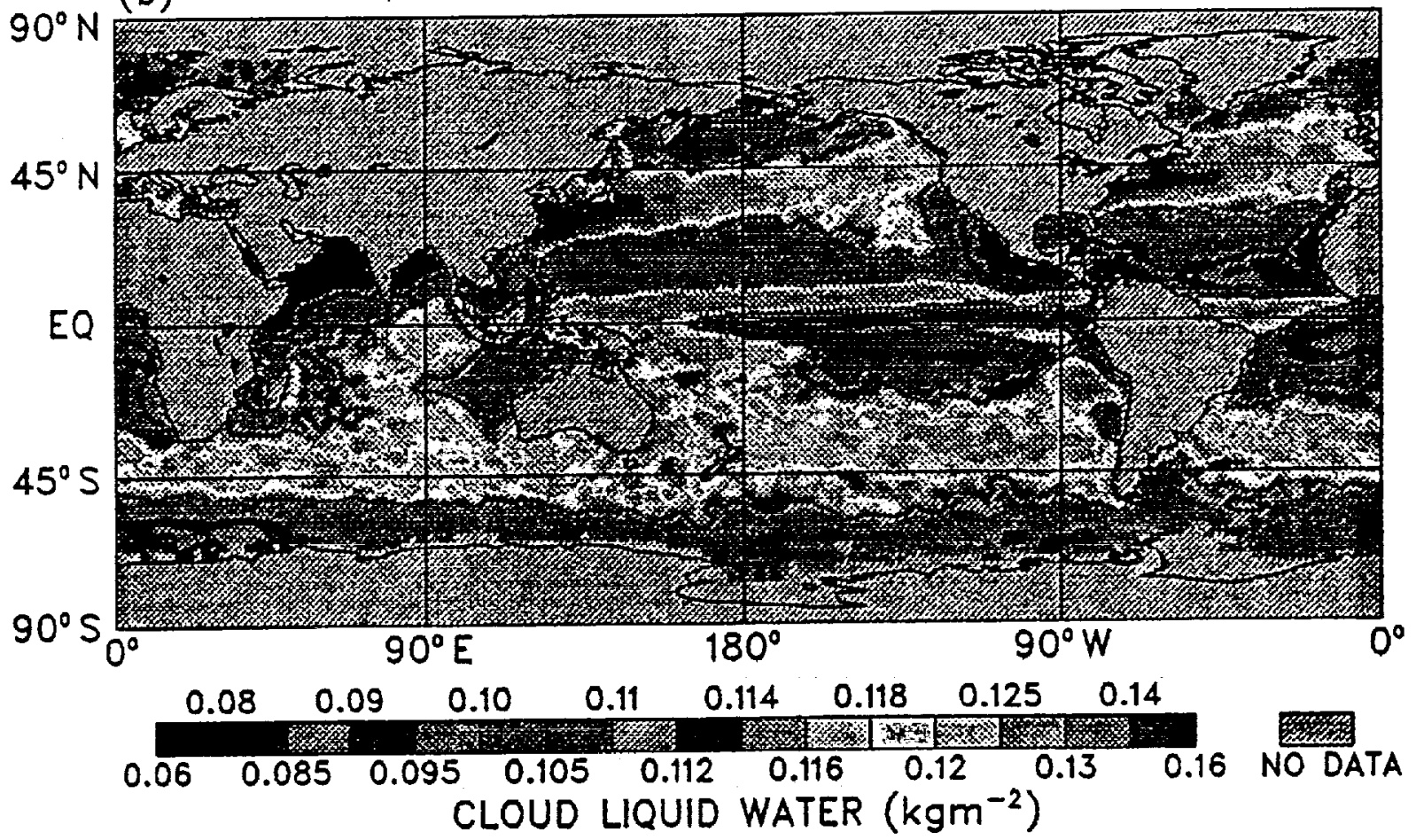

FiG. 4. Same as Fig. 3 except for (a) DJF and (b) MAM.

regions of very high seasonal swings in cloud LWP, sometimes as great as $30 \%$ of the annual mean.

Another region of large (greater than $0.025 \mathrm{~kg} \mathrm{~m}^{-2}$ ) and widespread variability extends along the eastem Asian coast into the far North Pacific and Bering Sea. The behavior is similar just south of Greenland, though to a slightly lesser degree. The large seasonal variability in these regions may be a result of continental influences. This is in contrast to the middle latitudes of the Southern Hemisphere where the impact of land masses is far less and the seasonal variability is smaller (less than $0.016 \mathrm{~kg} \mathrm{~m}^{-2}$ ). The lowest intra-annual variability (less than $0.0125 \mathrm{~kg} \mathrm{~m}^{-2}$ ), on the other hand, is generally located in regions whose climate is influenced by high pressure systems. When zonally averaged, the intra-annual variability varies from $10 \%$ to about $20 \%$ of the annual mean. In the monsoon regions and parts of the midlatitudes, the variability can be $30 \%$ 


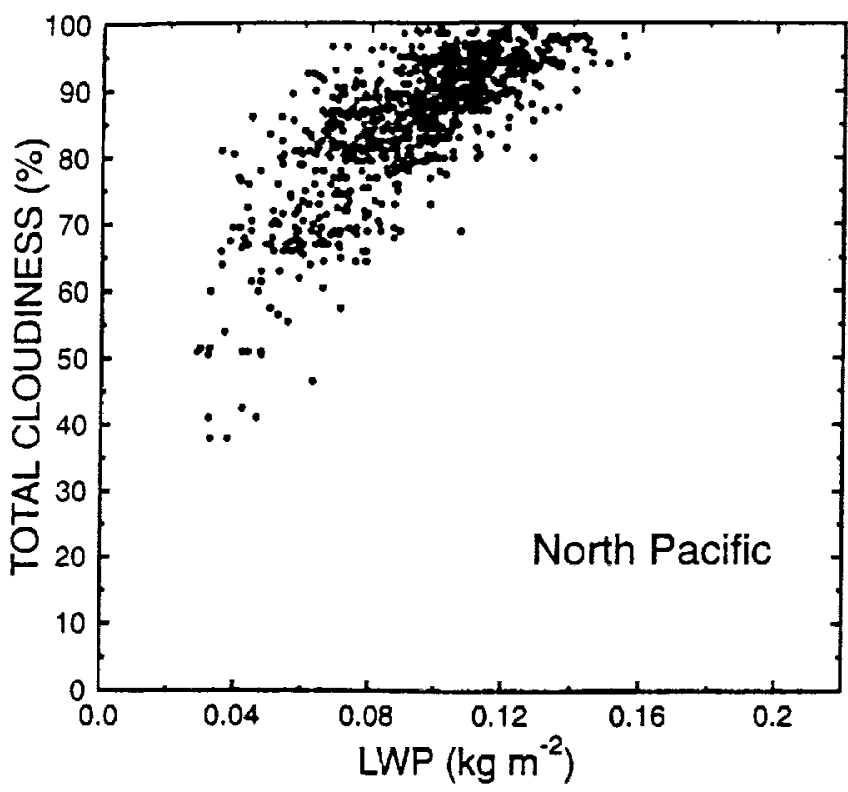

FIG. 5. Scatter diagram of monthly mean ISCCP total cloudiness (\%) versus SSM/I liquid water path $\left(\mathrm{kg} \mathrm{m}^{-2}\right)$ for the summer months from July 1987 to June 1991 over the North Pacific.

of the annual mean. The Northern Hemisphere also shows generally greater variability than the Southern Hemisphere.

Global and hemispheric average values of marine cloud LWP over the 53-month period are shown in Fig. 8 as a function of the month of the year. These quantities were derived by weighting the equal-angle grid boxes according to their area. The gray shading in the figure represents the interannual standard deviation. Over the globe the mean cloud LWP has a minimum of $0.111 \mathrm{~kg} \mathrm{~m}^{-2}$ in April and steadily increases to a maximum of $0.116 \mathrm{~kg} \mathrm{~m}^{-2}$ in December.

When separated into hemispheric means, the Northern Hemisphere exhibits greater seasonal change, with a low value of $0.107 \mathrm{~kg} \mathrm{~m}^{-2}$ in March and a peak value of about $0.118 \mathrm{~kg} \mathrm{~m}^{-2}$ in August. In the Southern Hemisphere, the seasonal variability is slightly less, and the nature of the seasonal cycle is very different than the Northem Hemisphere, aside from the obvious phase shift. For example, the lowest values of cloud LWP are spread out over a 4 to 5 month period and gradually increase to a maximum of $0.117 \mathrm{~kg} \mathrm{~m}^{-2}$ in January.

\section{Cloud liquid water temperature sensitivity analysis}

\section{a. Data and analysis method}

The source of data used in the following analysis are the Stage CI ISCCP cloud data products. Details concerning these datasets are described by Rossow and Schiffer (1991). The comparisons are made with daily mean cloud-top pressure and cloud LWP data on a $2.5^{\circ}$ $\times 2.5^{\circ}$ grid. Low clouds are defined the same as in
ISCCP; that is, clouds with cloud-top pressures between 680 and $1000 \mathrm{mb}$.

One difficulty with using daily mean gridded data is that although the mean cloud-top pressure may be greater than $680 \mathrm{mb}$, a large fraction of the grid box, in some instances, might be covered by higher-level cloudiness. As an attempt to ensure that the majority of clouds within the grid box are low level, we include only grid boxes where the low cloudiness (determined by ISCCP) is greater than $40 \%$. Another potential problem is the poor diumal sampling of the liquid water observations since these measurements are derived from only a single polar-orbiting satellite.

The atmospheric temperature data are also obtained from the ISCCP products, which are based on TIROS Operational Vertical Sounder (TOVS) satellite retrievals. Temperatures are given at seven pressure levels: $115,245,375,500,620,740$, and $900 \mathrm{mb}$, and the surface. The daily mean liquid water data are compared to the layer mean atmospheric temperature averaged over the day, which consists of the average temperature from $680 \mathrm{mb}$ to the surface.

The method of analyzing the cloud LWP-temperature relationship is very similar to that of Tselioudis et al. (1992), so as to facilitate a comparison of the results of that study with the present one. The cloud LWP and temperature data are collected together over specified time periods and/or latitudinal zones and sorted into temperature intervals, each with a width of $15 \mathrm{~K}$. The lower bound of the first interval occurs at $-25^{\circ} \mathrm{C}$, and each successive interval is shifted by $5 \mathrm{~K}$. The temperature representing each interval is simply the average of the temperature data within the interval. The natural logarithm of the cloud LWP $(L)$ is correlated to temperature using linear least-squares regression and the significance of the fit is determined from an $F$ test.

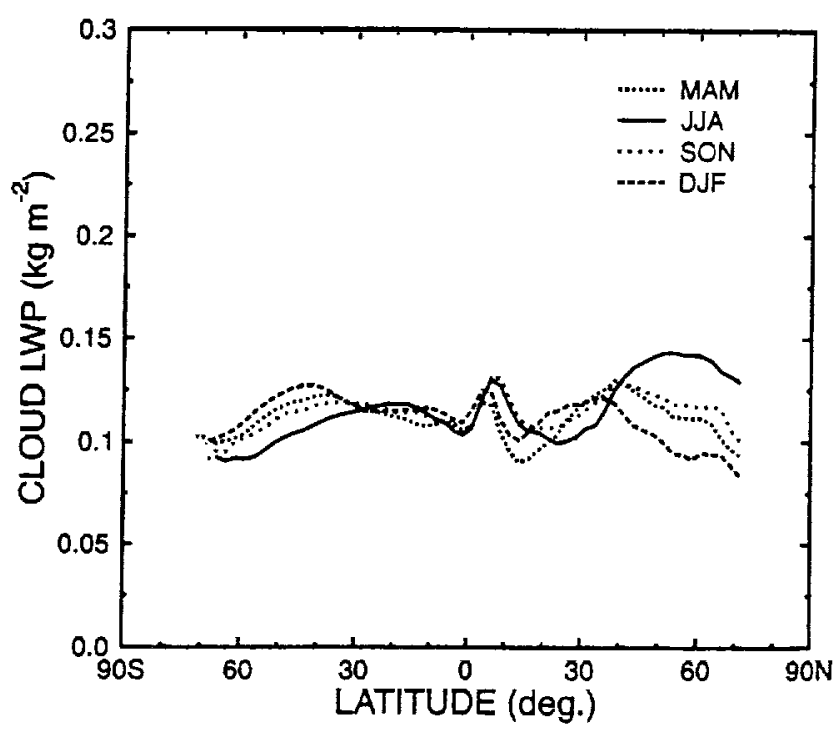

Fig. 6. Seasonal zonal averages of cloud liquid water path over the oceans for the data in Figs. 3 and 4. 


\section{b. Results}

Low clouds during JJA and DJF 1990 are found to have a globally averaged LWP of $0.095 \mathrm{~kg} \mathrm{~m}^{-2}$. In terms of zonally averaged behavior (not shown), the largest seasonal changes in liquid water for these clouds occur throughout the subtropics and poleward of about $45^{\circ} \mathrm{N}$. Our analysis also suggests that wintertime lowlevel water clouds over the middle to high latitude oceans tend to be less optically thick than during the summer, while the behavior is the opposite in the subtropics.

The relation between cloud liquid water and temperature can be characterized by the sensitivity parameter defined by Somerville and Remer (1984):

$$
f=\frac{1}{L} \frac{d L}{d T}=\frac{d \ln L}{d T}
$$

where for our application $L$ is the vertically integrated liquid water content of clouds below the $680-\mathrm{mb}$ level and $T$ is the average temperature of the atmosphere below this level.

The results of the global sensitivity analysis using data from JJA and DJF 1990 are given in Fig. 9. The quantity $d \ln L / d T$ is plotted as a function of the mean temperature of the 680-1000-mb layer for data extending from $70^{\circ} \mathrm{N}$ to $70^{\circ} \mathrm{S}$. Also shown for reference is the range in the sensitivity relationship one would expect based purely on adiabatic arguments for clouds of 100-mb thickness and varying height below the 700$\mathrm{mb}$ level, where the temperature is also the layer mean. These calculations are based on the results of Betts and Harshvardhan (1987). The observations indicate that the sensitivities for low clouds vary greatly with temperature (indicated as circles). A quasi-adiabatic behavior is observed for layer temperatures below about $7^{\circ} \mathrm{C}$, with sensitivities as high as $0.04 \mathrm{deg}^{-1}$. For temperatures greater than $7^{\circ} \mathrm{C}$ the sensitivity becomes negative and is as low as $-0.023 \mathrm{deg}^{-1}$ for temperatures near $15^{\circ} \mathrm{C}$.

One source of uncertainty in the cloud LWP-temperature relationship is the impact of a different liquid water threshold in defining cloudy FOVs. To investigate this, the analysis was repeated using a threshold pair of $0.032 / 0.016 \mathrm{~kg} \mathrm{~m}^{-2}$. These results are shown as the squares in Fig. 9. They demonstrate that the use of a different threshold changes the sensitivities by less than $0.01 \mathrm{deg}^{-1}$ for the global analysis.

The relationship of $d \ln L / d T$ to temperature for low clouds also undergoes sizeable variations on both seasonal and regional scales. Figure 10 presents the results of an analysis for the same datasets but separated into different latitude zones of midlatitude $\left(35^{\circ}-55^{\circ}\right)$, subtropics $\left(15^{\circ}-35^{\circ}\right)$, and Tropics $\left(0^{\circ}-15^{\circ}\right)$ for each of the two seasons. In the Northern Hemisphere in Fig. $10 \mathrm{a}$ all regions have negative or near-zero values of $d \ln L / d T$ except for temperatures less than about $-3^{\circ} \mathrm{C}$ (and a statistically insignificant point near $7^{\circ} \mathrm{C}$ ) for the midlatitudes during DJF. The Tropics show the greatest sensitivity of $d \ln L / d T$ to temperature with values ranging from about $-0.02 \mathrm{deg}^{-1}$ to $-0.085 \mathrm{deg}^{-1}$.

A direct comparison of the present results to those obtained by Tselioudis et al. (1992) is difficult since they used data every three hours and confined their analysis from 680 to $800 \mathrm{mb}$. In spite of the differences in these independent datasets, there exist many quantitative similarities. For example, their results show that the sensitivities for midlatitude clouds over the ocean are positive (though statistically insignificant) at the coldest temperatures but somewhat smaller than the results in Fig. 10a. The differences might be attributed to the effect of ice clouds in the observations of cloud optical depth. Their results also show that the sensitivities eventually crossover into negative values at higher temperatures, which are as low as $-0.04 \mathrm{~kg} \mathrm{~m}^{-1}$. These negative values are comparable to the values seen in Fig. 10a. In addition, the results of Tselioudis et al. give average subtropical and tropical values of about -0.05 $\mathrm{kg} \mathrm{m}^{-1}$, which are generally consistent with the average of the seasonal results in Fig. 10a, although the liquid water results in the subtropics tend to be of slightly smaller magnitude.

The results for the Southern Hemisphere in Fig. 10b yield a somewhat different behavior in the temperature dependence and magnitudes of $d \ln L / d T$. While the warmest oceans of both hemispheres are primarily associated with negative values of $d \ln L / d T$, the suburopical values are smaller in the Southern Hemisphere (on average about $-0.01 \mathrm{deg}^{-1}$, but sometimes positive), and the tropical values are more sensitive to temperature, ranging from 0 to almost $-0.09 \mathrm{deg}^{-1}$. Furthermore, the seasonal change in the southern midlatitudes at the coldest temperatures is far more dramatic than in the northern latitudes.

Because of the coarse resolution of the measurements it is difficult to isolate the cloud LWP-temperature relationship completely from other factors that determine the amount of cloud liquid water over the grid box, such as changes in cloud thickness and cloud amount. The effects of variations in cloud thickness are reduced by using low clouds. To minimize the influence of cloudiness on the sensitivity relationships the data were analyzed again but using only grid boxes where ISCCP total cloudiness exceeded $80 \%$. For the global analysis the differences in the results obtained for these conditions with those presented in Fig. 9 are fairly small. The data become shifted systematically toward positive values of $d \ln L / d T$ relative to the curve in Fig. 9 by about $0.01 \mathrm{deg}^{-1}$. However, for the regional and seasonal analyses in Fig. 10, the differences are more significant. For example, although the basic temperature dependence of $d \ln L / d T$ is retained for most regions, the differences in magnitude of the sensitivities are sometimes as great as $0.05 \mathrm{deg}^{-1}$.

In summary, these results indicate that the LWP of low clouds in the Tropics and in many areas of the 
(a)

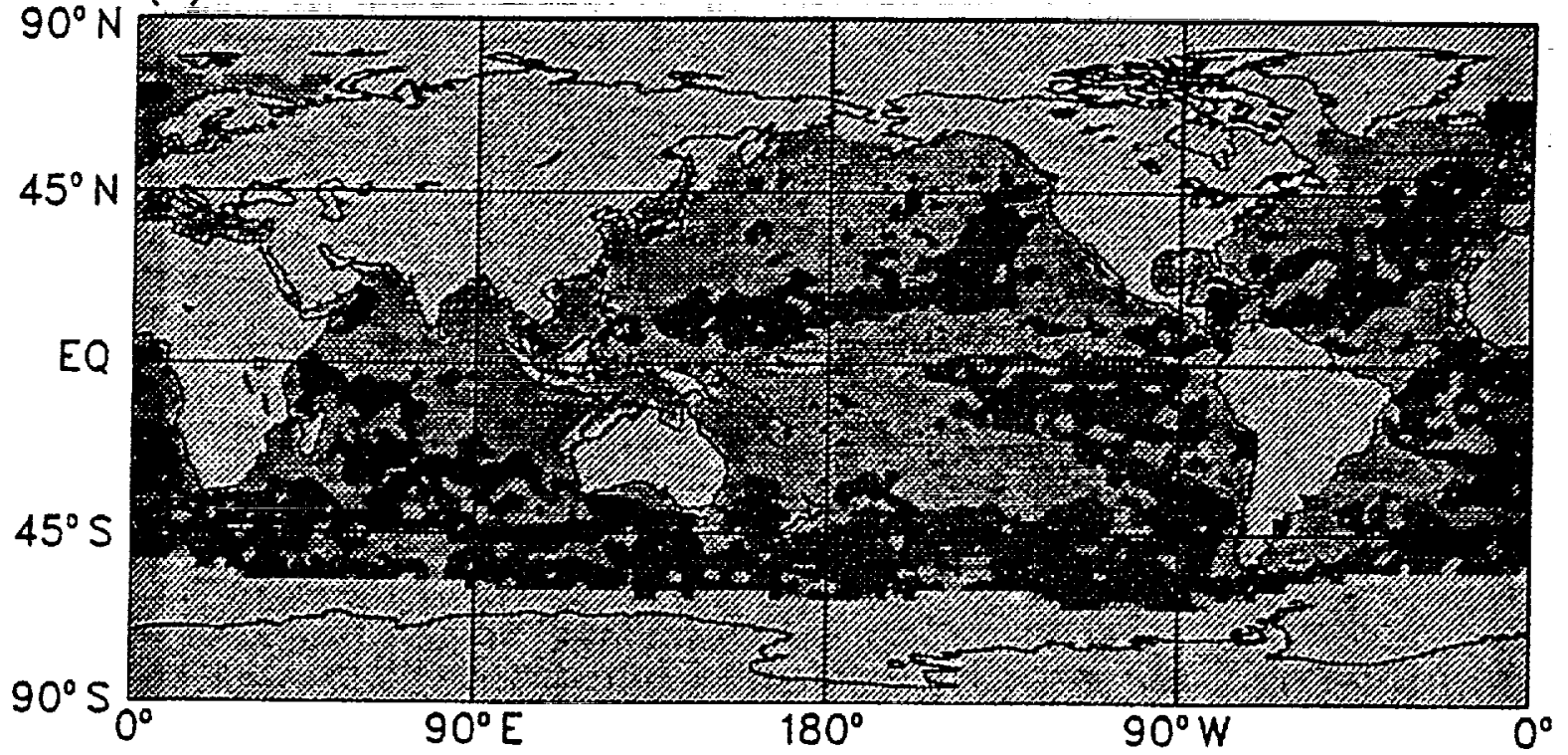

(b)
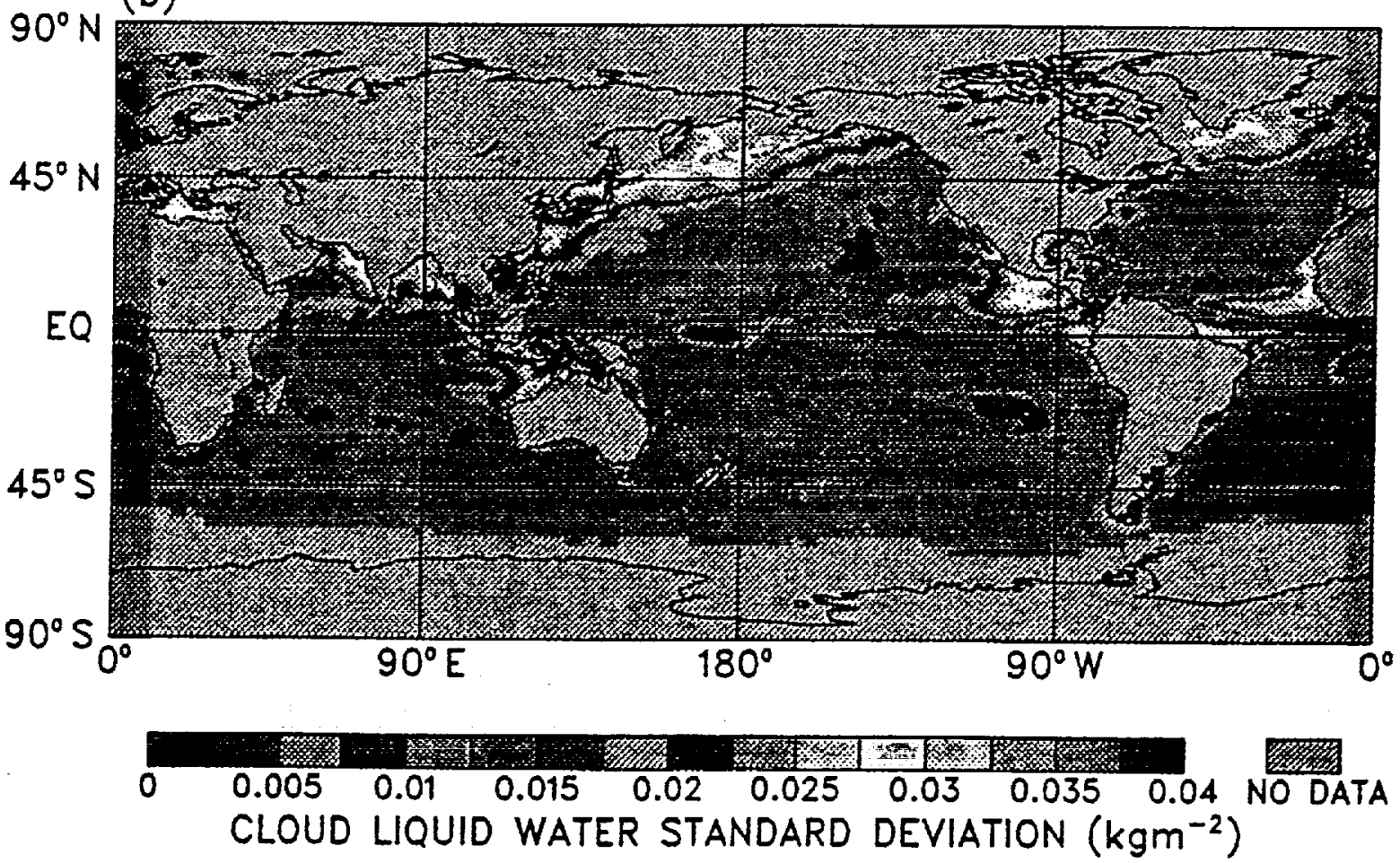

FIC. 7. Global distributions of (a) interannual and (b) intra-annual standard deviations of SSM/I cloud liquid water path $\left(\mathrm{kg} \mathrm{m}^{-2}\right)$.

subtropics and midlatitudes in the summer tends to decrease with increasing temperature, while the relationship becomes generally quasi-adiabatic at colder temperatures in the midlatitudes. Tselioudis et al. (1992), in their comprehensive study, concluded that variations of cloud optical depth with temperature were caused primarily by physical processes occurring within the clouds. They proposed a microphysical explanation for the negative correlations they found between optical depth and temperature, ascribing them to more efficient precipitation processes. They also acknowledged the possible impact of boundary layer dynamics in strongly influencing these temperature sensitivities for certain cloud types.

The primary objective of this section was to report on the observed sensitivities between cloud LWP and 

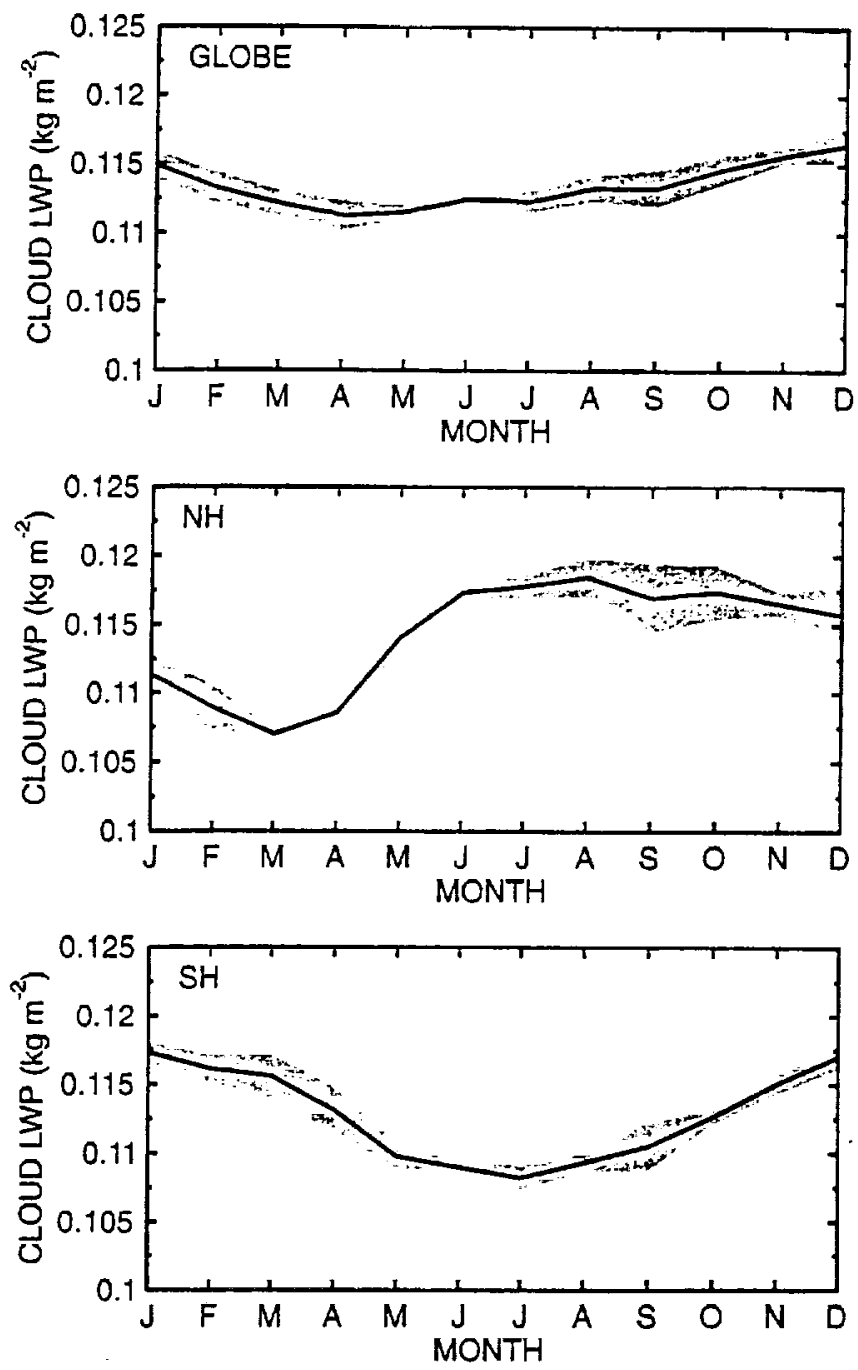

FiG. 8. Areally weighted averages of cloud LWP for the globe (top), Northern Hemisphere (middle), and Southern Hemisphere (bottom) as a function of month. Gray shading represents interannual variation as one standard deviation above and below the data points.

temperature. A thorough examination of the possible causes of these relationships is beyond the scope of this study. Clearly, the challenge in future studies will be to establish the relative roles of microphysical and dynamical processes in determining these cloud LWPtemperature sensitivities.

\section{Cloud liquid water and the earth radiation budget}

\section{a. Data sources and analysis method}

The top-of-the-atmosphere (TOA) broadband radiative fluxes used in the following comparisons are obtained from instantaneous measurements of the scanner instruments aboard the NOAA-10 satellite and the Earth Radiation Budget Satellite (ERBS). The shortwave (SW) channel of the scanner covers the spectral region from 0.2 to $5 \mu \mathrm{m}$ and the longwave (LW) channel ranges from 5 to $50 \mu \mathrm{m}$. The ERBS scanner has footprint dimensions (along-track by cross-track) at nadir of roughly $48 \mathrm{~km} \times 32 \mathrm{~km}$, while the scanner on the $N O A A-I O$ is slightly larger at about $65 \mathrm{~km} \times 44 \mathrm{~km}$. The footprint size increases dramatically as the instrument looks farther away from nadir. A more complete description of the instrument, including its operation and calibration, is discussed by Kopia (1986).

Collocation of the Earth Radiation Budget Experiment (ERBE) scanner and SSM/I measurements is achieved simply by finding those pixels whose center points are within $10 \mathrm{~km}$ of one another. Unfortunately, prior to 1989 , the DMSP F-8 satellite experienced significant geolocation errors (often more than $20-30 \mathrm{~km}$ ) arising principally from ephemeris errors (Poe and Conway 1990). To reduce these geolocation errors we used the correction described by Wentz (1991), which is accurate to within about $10 \mathrm{~km}$.

The comparisons are confined to mostly low-level, summertime clouds so as to diminish the effects of ice particles on the albedo. The regions we have chosen to focus on are the North Pacific and North Atlantic. A number of "coincident" matches (i.e., within seconds to several minutes) were found in the months of June and July 1988 in these regions. A summary of the general locations, dates, and times of the matches (those which provided comparisons that satisfied the strict criteria described below) is shown in Table 1.

Low-level clouds were identified by $\mathrm{LW}$ cloud forcing values below $45 \mathrm{~W} \mathrm{~m}^{-2}$. This threshold is based on

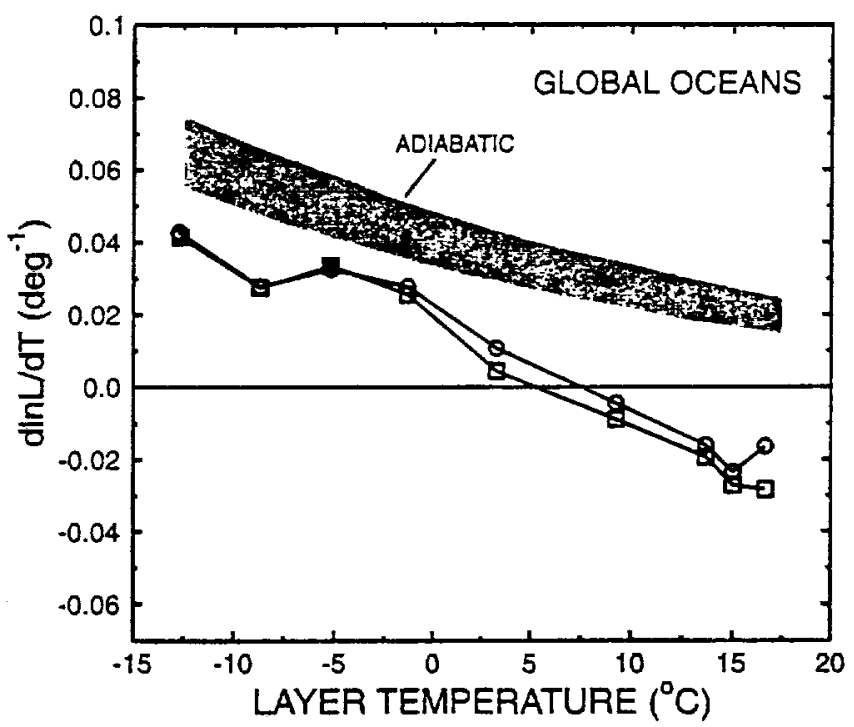

FIG. 9. Global relationship between $d \ln U d T\left(\mathrm{deg}^{-1}\right)$ for low clouds versus the temperature $\left({ }^{\circ} \mathrm{C}\right)$ of the atnospheric layer from $680 \mathrm{mb}$ to the surface. Each symbol represents a temperature interval of width $15 \mathrm{~K}$. The observations are given for different liquid water thresholds used to define cloudy fields of view, i.e., the liquid water threshold pairs of $0.048 / 0.024 \mathrm{~kg} \mathrm{~m}^{-2}$ (circles) and $0.032 / 0.016 \mathrm{~kg} \mathrm{~m}^{-2}$ (squares). The light shading indicates the range of the relationship derived from an adiabatic assumption for clouds of 100 -mb thickness and at different heights from 700 to $1000 \mathrm{mb}$. 

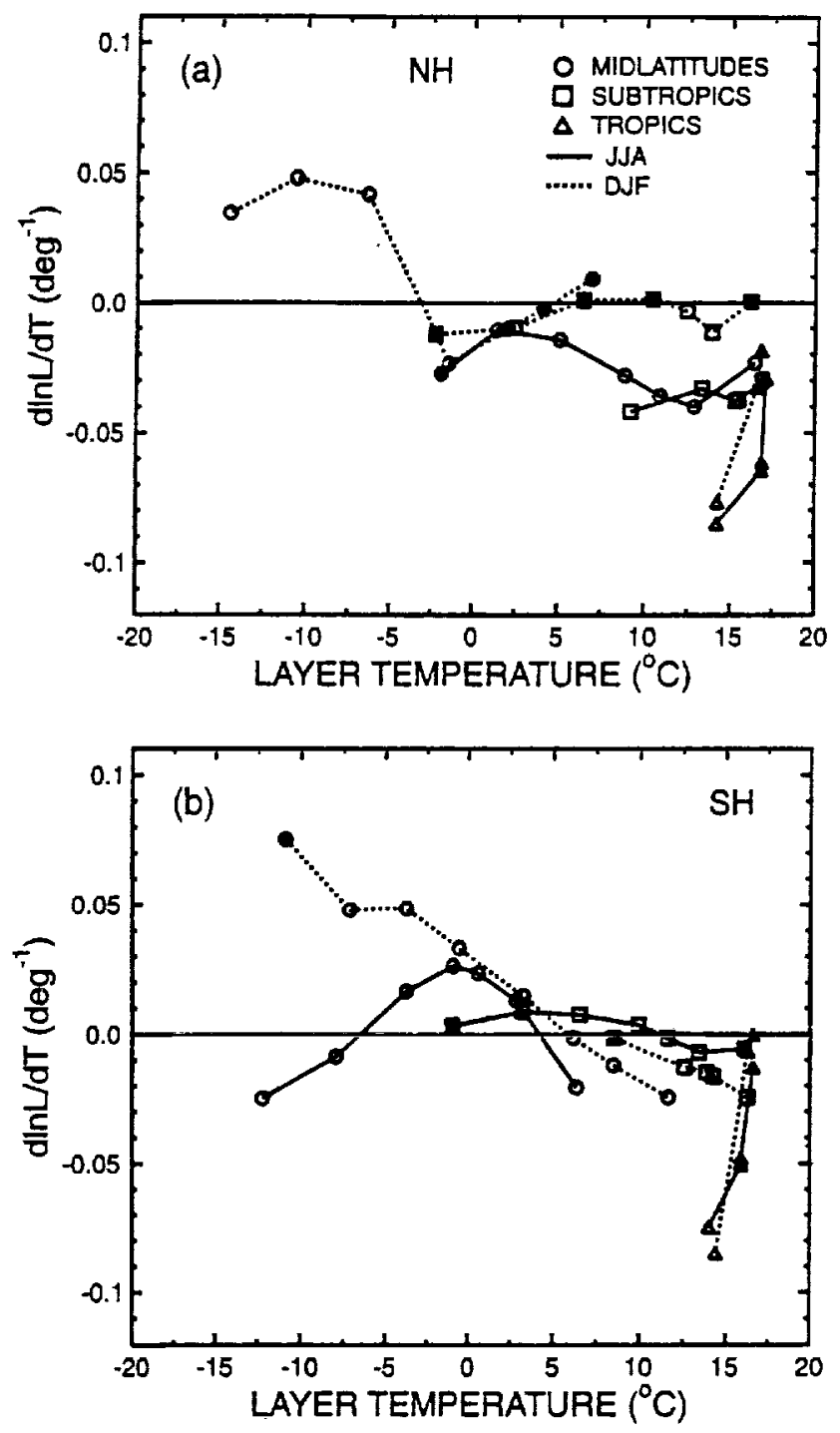

Fic. 10. Scatter diagrams of $d \ln L / d T$ (deg ${ }^{-1}$ ) for low clouds as a function of temperature $\left({ }^{\circ} \mathrm{C}\right)$ separated into midlatitude $\left(35^{\circ}-55^{\circ}\right)$, subtropical $\left(15^{\circ}-35^{\circ}\right)$, and tropical $\left(0^{\circ}-15^{\circ}\right)$ latitude regions and the seasons of JJA and DJF for the (a) Northem Hemisphere and (b) Southern Hemisphere. Filled symbols are data points with correlations below the $99 \%$ significance level.

the results of Ackerman et al. (1992, 1994), where instantaneous measurements of $\mathrm{LW}$ cloud forcing for stratus clouds indicated values of up to $40-50 \mathrm{~W} \mathrm{~m}^{-2}$. Clear sky LW fluxes were determined from average measurements, for the same month, within $1^{\circ}$ bins as a function of latitude.

To minimize the obvious effects of cloud brokenness on the SW measurements we chose only overcast FOVs, which were determined by the ERBE scene identification. Also, while the SSM/I's 37-GHz channels (alongtrack and cross-track dimensions of $37 \mathrm{~km}$ $\times 29 \mathrm{~km}$ ) and the ERBE scanner have comparable resolutions when the ERBE scanner looks at nadir, the differences in resolution can become substantial at large viewing angles. Thus, the comparisons are limited to ERBE scanner viewing angles of less than $20^{\circ}$. Another reason for using measurements near nadir is to avoid the slight dependence of the albedo on the viewing zenith angle, which is discussed by Suttles et al. (1992). Furthermore, because of the uncertainties in the SSM/I geolocation and in order to reduce the noise in the liquid water retrievals, we used $37-\mathrm{GHz}$ brightness temperatures averaged from the collocated pixel and the four nearest pixels.

In the comparisons, the solar zenith angles ranged from $70^{\circ}$ to $86^{\circ}$ since the DMSP $F-8$ satellite flies near the terminator. To eliminate the solar zenith angle dependence of the albedo measurements, the albedos were normalized to a common solar zenith angle of $75^{\circ}$ using the ERBE directional model for overcast conditions. The amount of adjustment resulting from the normalization was very small for all the observations because of the overcast conditions and since the sun angles deviated at most by $10^{\circ}$ from the reference angle of $75^{\circ}$. The clear sky albedo, which was required for computing the $S W$ cloud forcing, was determined from the appropriate directional model as well [see Dlhopolsky and Cess (1993) for a description of the ERBE directional model for clear sky ocean ].

The specification of the effective cloud temperature for the liquid water retrievals was the same as for the global analysis - that is, the average of the monthly mean surface temperature and a climatic midlevel cloud-top temperature. Unfortunately, coincident 11 $\mu \mathrm{m}$ measurements were unavailable for both the $E R B S$ and NOAA-10 comparisons to aid in determining the cloud temperature. An attempt was also made to improve the oxygen transmission and the surface skin temperature in the retrieval model by using temperature profiles and skin temperatures derived from the TOVS

TABLE 1. Date, time, and approximate location of the coincident satellite matches in the earth radiation budget and cloud liquid water comparisons for 1988.

\begin{tabular}{rccccc}
\hline \hline \multicolumn{7}{c}{$E R B S$ and DMSP F-8 } \\
Case & Latitude & Longitude & Month & Day & GMT \\
\hline 1 & $40^{\circ}-54^{\circ} \mathrm{N}$ & $169^{\circ} \mathrm{E}-166^{\circ} \mathrm{W}$ & June & 1 & 1719 \\
2 & $48^{\circ}-57^{\circ} \mathrm{N}$ & $149^{\circ}-170^{\circ} \mathrm{W}$ & June & 16 & 2124 \\
3 & $54^{\circ}-58^{\circ} \mathrm{N}$ & $139^{\circ}-154^{\circ} \mathrm{W}$ & June & 18 & 0540 \\
4 & $55^{\circ}-56^{\circ} \mathrm{N}$ & $13^{\circ}-29^{\circ} \mathrm{W}$ & June & 20 & 2034 \\
5 & $56^{\circ}-58^{\circ} \mathrm{N}$ & $140^{\circ}-153^{\circ} \mathrm{W}$ & June & 22 & 0450 \\
6 & $55^{\circ}-58^{\circ} \mathrm{N}$ & $11^{\circ}-22^{\circ} \mathrm{W}$ & June & 24 & 1944 \\
7 & $40^{\circ}-45^{\circ} \mathrm{N}$ & $162^{\circ}-164^{\circ} \mathrm{W}$ & July & 23 & 1644 \\
8 & $50^{\circ}-52^{\circ} \mathrm{N}$ & $24^{\circ}-29^{\circ} \mathrm{W}$ & July & 26 & 0739 \\
& & & & & \\
& & & & & \\
9 & $45^{\circ}-58^{\circ} \mathrm{N}$ & $151^{\circ}-157^{\circ} \mathrm{W}$ & July & 7 & 0512 \\
10 & $44^{\circ}-57^{\circ} \mathrm{N}$ & $44^{\circ}-50^{\circ} \mathrm{W}$ & July & 7 & 2208 \\
11 & $42^{\circ}-48^{\circ} \mathrm{N}$ & $29^{\circ}-45^{\circ} \mathrm{W}$ & July & 17 & 2150 \\
12 & $42^{\circ}-58^{\circ} \mathrm{N}$ & $142^{\circ}-149^{\circ} \mathrm{W}$ & July & 18 & 0434 \\
13 & $48^{\circ}-49^{\circ} \mathrm{N}$ & $162^{\circ}-164^{\circ} \mathrm{W}$ & July & 28 & 0556 \\
\hline
\end{tabular}


on the NOAA-9 and NOAA-1O satellites [which are part of the National Environmental Satellite Data and Information Service (NESDIS) TOVS sounding products ]. Monthly mean, $2.5^{\circ} \times 2.5^{\circ}$ gridded datasets of skin temperature and oxygen transmission were used in the retrievals. The oxygen transmission was computed for each sounding using the millimeter wave absorption model of Liebe et al. (1993). Finally, we used a somewhat more conservative liquid water threshold of $0.35 \mathrm{~kg} \mathrm{~m}^{-2}$ to separate retrievals for nonprecipitating and precipitating clouds.

\section{b. Results}

Theoretical calculations of the albedo at the TOA for piane-parallel clouds were done for different cloud LWP and for cloud droplet effective radii $\left(r_{e}\right)$ of 5,10 , 15 , and $20 \mu \mathrm{m}$. These values of $r_{e}$ are thought to represent a typical range for most stratiform-type clouds, although $20 \mu \mathrm{m}$ is probably an extreme value. In situ measurements of $r_{e}$ in marine stratocumulus (Slingo et al. 1982; Stephens and Platt 1987; Albrecht et al. 1988) and arctic stratus clouds (Herman and Curry 1984) have been shown to range from about 5 to $10 \mu \mathrm{m}$.

The TOA albedo was derived from the two-stream model described by Stackhouse and Stephens (1991). The model consists of $250 \mathrm{SW}$ bands from 0.28 to 3.85 $\mu \mathrm{m}$ and includes absorption by water vapor, $\mathrm{CO}_{2}, \mathrm{O}_{2}$ and $\mathrm{O}_{3}$, and Rayleigh scattering. The $\mathrm{O}_{3}$ absorption is based on the cross-section data used in the study of Stamnes and Tsay (1990). We implemented a modified discrete ordinate method to approximate the direct backscatter fraction as done by Stackhouse and Stephens (1991). A surface albedo of 0.21 was assumed for each spectral band, which was based on the ERBE clear sky directional model for a solar zenith angle of $75^{\circ}$. The profiles of temperature and humidity were taken from a typical sounding over the North Pacific during the summer and the $\mathrm{O}_{3}$ density profile was obtained from McClatchey et al. (1972) for the midlatitude summer. The cloud occupied the layer from 1 to $3 \mathrm{~km}(889-693 \mathrm{mb})$. Lastly, the cloud optical properties (i.e., extinction, single scatter albedo, and asymmetry factor) were computed for each spectral band via Mie theory using a representative lognormal size distribution for marine stratocumulus.

The results of the albedo and cloud LWP comparisons for overcast, low-level clouds in the North Pacific and Atlantic are presented in Figs. 11 and 12. The comparisons are shown separately for the ERBS and the NOAA-10 satellite because of the differences in footprint dimensions of the two ERBE sensors. The observations in Fig. 11 show a definite rise in the albedo with increasing cloud LWP for LWP less than about $0.15-0.2 \mathrm{~kg} \mathrm{~m}^{-2}$ and indicate little or no sensitivity of the albedo to changes in LWP for larger LWPs. This behavior is in general agreement with theory. The relationship is similar for the NOAA-10 satellite in Fig. 12 but is somewhat less distinct.
Theory and observations are also shown to agree, in a general sense, with respect to the size of the cloud droplets. However, there do exist some large discrepancies in the results. A few anomalously high albedos (greater than 0.85 ) in Figs. 11 and 12 are associated with very large solar zenith angles $\left(84^{\circ}-86^{\circ}\right)$ and indicate that the $S W$ measurements may be suspect. Some of the data points corresponding to drop sizes of less than $5 \mu \mathrm{m}$ (particularly in Fig. 11) are possibly a result of the SW effects of ice particles, which may be present in some of the ERBE scanner FOVs. Also, several data points with drop sizes exceeding $20 \mu \mathrm{m}$ for cloud LWP greater than $0.2 \mathrm{~kg} \mathrm{~m}^{-2}$ in Fig. 11 are likely caused by precipitation contamination of the LWP retrievals.

The mean values of $r_{e}$ from Figs. 11 and 12 (excluding outlying points) are determined to be 10.6 and $13.0 \mu \mathrm{m}$, respectively, with standard deviations of 4.8 and $6.2 \mu \mathrm{m}$. Overall, the mean and standard deviation are $11.1 \mu \mathrm{m}$ and $5.2 \mu \mathrm{m}$. The extent of these values are consistent with satellite estimates of $r_{e}$ for warm clouds in the North Pacific and North Atlantic during July from the study of Han et al. (1994), where sizes ranged from about 11 to $15 \mu \mathrm{m}$.

While some of the scatter in the observations is perhaps attributed to fluctuations in $r_{e}$, the relatively large magnitude of these variations points to other effects that may be of comparable importance in influencing the observed albedo-LWP relationships. For example, uncertainties in the LWP retrievals and SW fiuxes may cause additional variation in these relationships. Enors in the ERBE instantaneous fluxes (in terms of one standard deviation) are estimated to be $12 \%$ for the SW and 5\% for the LW (Wielicki et al. 1995). These errors are dominated by uncertainties in the ERBE angular dependence models (ADMs), which are used to convert the measured radiances to hemispheric fluxes. The $\mathrm{ADM}$ errors may be especially important for the present comparison since the upwelling radiation field is expected to be highly anisotropic due to the very low sun angles.

Macrophysical cloud effects also have the potential to impact the SW measurements. For instance, Cahalan et al. (1994) investigated the effects of in-cloud variability on the albedo using fractal stratocumulus clouds and found plane-parallel biases of typically $10 \%$ for a solar zenith angle of $60^{\circ}$. Also, radiative transfer simulations using a two-dimensional model suggest that the effects of cloud variability is most appreciable when the sun is low (P. Stackhouse Jr. 1995, personal communication).

The errors associated with the two-stream radiative transfer model are yet another source of uncertainty in the albedo-LWP relationships. Two-stream methods are convenient because of their simplicity, but they have certain limitations and their performance can depend greatly on the solar geometry and the cloud optical properties. In an evaluation of several two-stream 


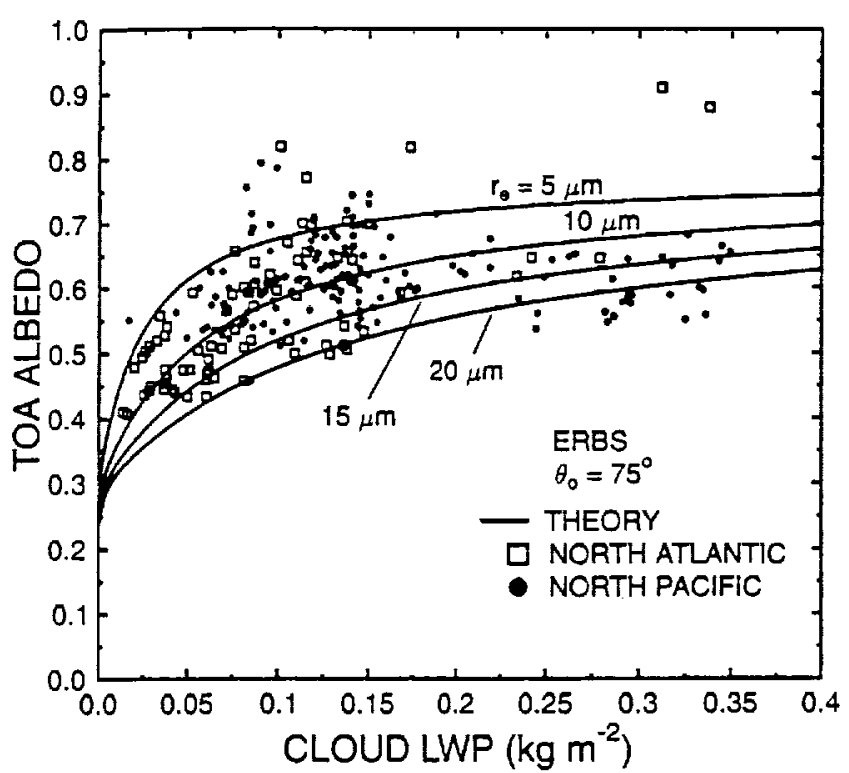

Fic. 11. Scatter diagram of instantaneous broadband albedo measurements from $E R B S$ at a solar zenith angle $\left(\theta_{0}\right)$ of $75^{\circ}$ versus coincident SSM/I retrievals of cloud LWP for low clouds over the North Pacific (filled circles) and North Atlantic (squares) during June and July 1988. Also shown are mode! simulated top-of-the-atmosphere albedos for different cloud drop effective radii $\left(r_{e}\right)$ based on a twostream model (Stackhouse and Stephens 1991) and assuming a surface albedo of 0.21 .

methods, King and Harshvardhan (1986) found that for both conservative and nonconservative scattering the ertors in the albedo for nearly all the methods they tested were within $5 \%-10 \%$ for the cloud optical depths and solar zenith angle considered in this study. Finally, other less important sources of variability in the albedo-LWP relationships might include collocation errors and, possibly, differences in the viewing geometry of the SSM/I and ERBE scanner.

Another relationship to consider, which is also of great significance to climate, is that between LWP and the net cloud forcing. The instantaneous ERBS net cloud forcing versus LWP is presented in Fig. 13 for LWPs below $0.2 \mathrm{~kg} \mathrm{~m}^{-2}$. The relationship is not shown for larger LWPs since $C_{\text {ner }}$ does not vary with changing LWP. The net cloud forcing $C_{\text {net }}$ is defined as

$$
C_{\text {net }}=\mu_{0} F_{0}\left(\alpha_{\mathrm{clr}}-\alpha_{\mathrm{obs}}\right)+C_{\mathrm{Lw}},
$$

where $\mu_{0}$ is the cosine of the solar zenith angle, $F_{0}$ is the distance-corrected solar constant, $\alpha_{\text {cir }}$ is the clear sky albedo, $\alpha_{\text {obs }}$ is the observed albedo, and $C_{\mathrm{LW}}$ is the $\mathrm{LW}$ cloud forcing. Also shown in this figure is the line determined from a least absolute deviations analysis. The observations reveal that the low-level clouds of the North Atlantic and Pacific produce a $-25 \mathrm{~W} \mathrm{~m}^{-2}$ change in the net cloud forcing at the TOA for every $0.05 \mathrm{~kg} \mathrm{~m}^{-2}$ increase in their LWP. Of course, these results are only valid for a solar zenith angle of $75^{\circ}$. The sensitivity of $C_{\text {net }}$ to changes in LWP is expected to be greater for the same range of LWP when the sun is, for example, at zenith.

\section{Conclusions}

Satellite measurements from the SSM/I and the ERBE scanners have been used to study the large-scale characteristics and radiative effects of integrated cloud liquid water over the oceans. The 53 months of cloud LWP observations exhibited many outstanding spatial characteristics. Some of the largest liquid water amounts observed (often greater than $0.14 \mathrm{~kg} \mathrm{~m}^{-2}$ ), which were possibly caused by prolific stratus cloudiness, were located in the North Pacific and Atlantic during the summer when these regions are under the controlling influence of high pressure systems and strong static stability. In the Northern Hemisphere during fall, winter, and spring the eastward progression of midlatitude weather systems produced a narrow belt of elevated cloud LWP values. Extensive and large cloud LWP values, often more than $0.13 \mathrm{~kg} \mathrm{~m}^{-2}$ and sometimes exceeding $0.15 \mathrm{~kg} \mathrm{~m}^{-2}$, occurred along these storm pathways. In areas of the Tropics where moisture convergence and convection is especially strong and widespread the cloud LWPs were expectedly high (ranging from 0.13 to more than $0.15 \mathrm{~kg} \mathrm{~m}^{-2}$ ). These areas include the ITCZ in the Pacific and Atlantic and the intense convection in the westem equatorial Pacific and Indian Ocean. The zonal distribution of cloud LWP consists of three primary maxima. The peaks in the midlatitudes are thought to be associated with storm activity. Another maximum in the Tropics is an indicator of tropical convection, which is caused mainly by the ITCZ in the Pacific.

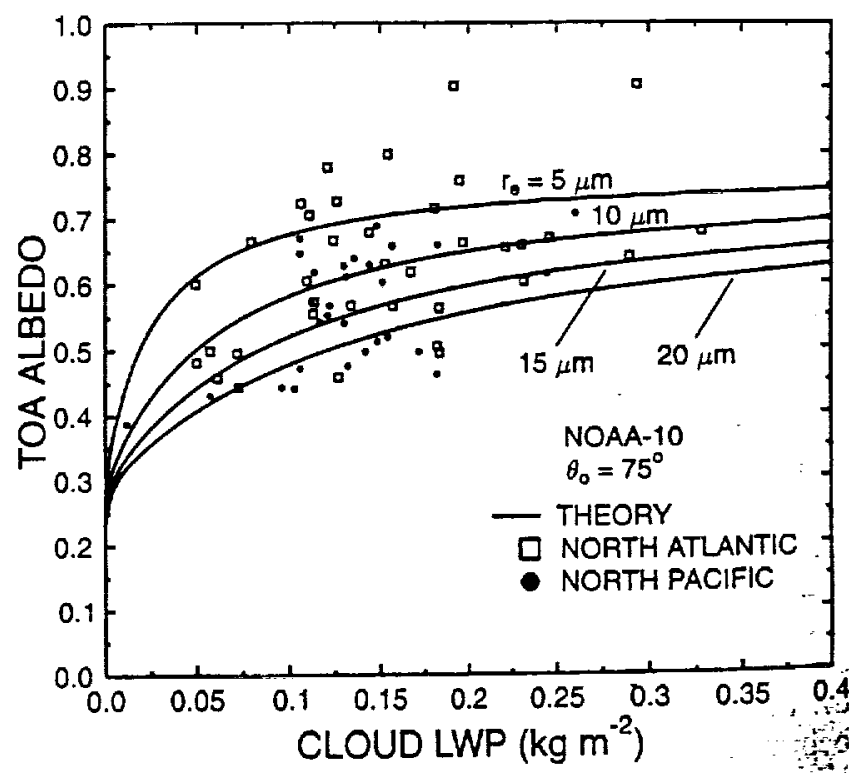

Fig. 12. Same as Fig. 11 but for albedo measurements from NOAA-1O and only for July 1988. 


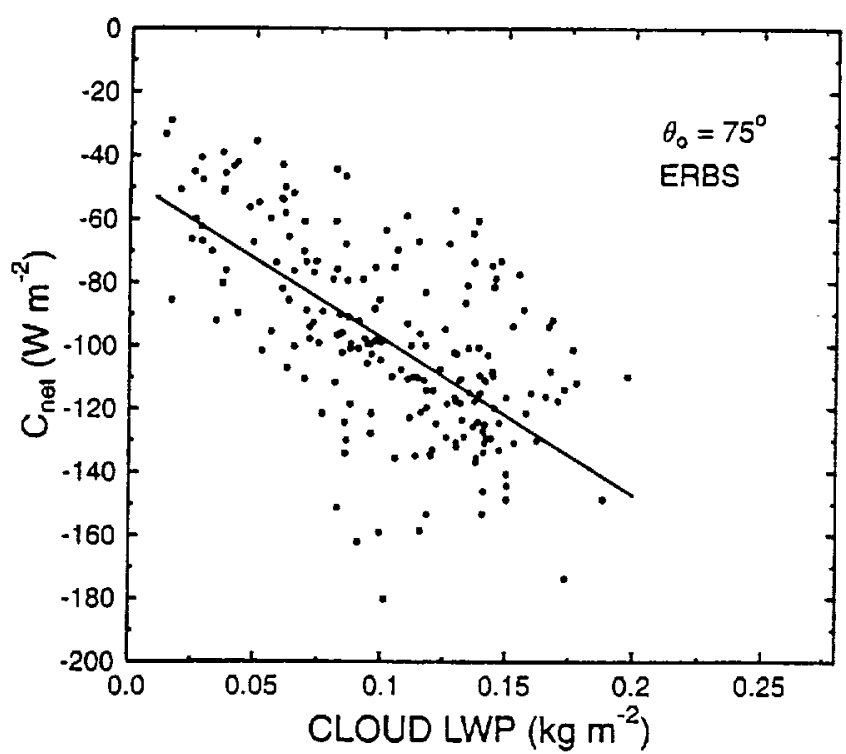

FiG. 13. ERBS measurements of the net cloud forcing $\left(\mathrm{W} \mathrm{m}^{-3}\right)$ versus cloud LWP for low clouds with LWPs less than $0.2 \mathrm{~kg} \mathrm{~m}^{-2}$ and at a solar zenith angle $\left(\theta_{0}\right)$ of $75^{\circ}$. Also shown is a linear fit from a least absolute deviations analysis.

The main conclusions of this study can be summarized as follows:

(i) The spatial distribution of integrated cloud liquid water over the oceans has many characteristics. that are consistent with known large-scale dynamical features. Further research will be needed to quantify the effects of these dynamical processes. The average amount of marine cloud LWP over the globe is estimated to be $0.113 \mathrm{~kg} \mathrm{~m}^{-2}$, while low clouds have an average of about $0.095 \mathrm{~kg} \mathrm{~m}^{-2}$. The seasonal departures of cloud LWP, when averaged over $2.5^{\circ} \times 2.5^{\circ}$ regions, are typically between $15 \%$ and $25 \%$ of the annual mean and are largest in the Tropics and northem midlatitudes.

(ii) The LWP of low clouds is determined to be negatively correlated with temperature throughout the Tropics and in parts of the subtropics and midlatitudes during the summer. This is in general agreement with previously published results based on observations of cloud optical depth, although there exist quantitative differences. At higher latitudes the correlations are reversed and assume a quasi-adiabatic behavior. This result is also consistent with the sensitivities deduced by Somerville and Remer (1984) based on aircraft measurements of high-latitude clouds over Russia. The relationships also exhibit significant variability on both seasonal and regional scales. These results cannot be used to imply a global cloud-climate feedback given that the observed sensitivities change sign depending on latitude. Since our results are based only on six months of data, many more years of data will be necessary to confirm the LWP-temperature sensitivities derived in this study. (iii) A comparison of coincident and collocated observations of cloud LWP and albedo for summertime low-level clouds in the North Pacific and Atlantic revealed relationships that are, for the most part, consistent with plane-parallel theory. The mean and standard deviation of $r_{e}$ inferred from the albedo-LWP relationships are 11.1 and $5.2 \mu \mathrm{m}$, respectively. It is proposed that the large variation in $r_{e}$ indicates that other factors, including errors in the cloud LWP and SW flux retrievals, may be a significant source of uncertainty in the albedo-LWP relationships. Further comparisons of the cloud LWP and the net cloud forcing for low clouds of LWP less than $0.2 \mathrm{~kg} \mathrm{~m}^{-2}$ show a change in the net cloud forcing of $-25 \mathrm{~W} \mathrm{~m}^{-2}$ for a $0.05 \mathrm{~kg} \mathrm{~m}^{-2}$ increase in LWP at a solar zenith angle of $75^{\circ}$. In contrast, the net cloud forcing for clouds with LWPs greater than about $0.2 \mathrm{~kg} \mathrm{~m}^{-2}$ exhibits no sensitivity to changes in LWP.

In a follow-up study we plan to extend the albedoLWP comparison to other regions and time periods. Future projects, such as TRMM and the Earth Observing System (EOS), will include both radiation budget scanners and multichannel microwave radiometers on the satellite platforms. This should allow for many more coincident comparisons between albedo and cloud LWP and also provide an opportunity to determine these relationships at smaller solar zenith angles.

Acknowledgments. We thank I. Wittmeyer for kindly supplying the TOVS data. This research was funded, in part, by NASA Grants NAG8-981 and NAGW2700, and NOAA Grant NA37RJ0202. S. Christopher was funded by NASA Grant NAGW-3966 and T. Greenwald was also supported by a NASA Fellowship in Global Change Research, Grant NGT-30046.

\section{APPENDIX}

\section{Microwave Retrieval Method}

From Greenwald et al. (1993), $W$ and $L$ can be expressed as

$$
\begin{aligned}
& W=\frac{\tau_{1} \kappa_{137}-\tau_{2} \kappa_{i 19 / 22}}{\delta} \\
& L=\frac{\tau_{2} \kappa_{w 19 / 22}-\tau_{1} \kappa_{w .37}}{\delta},
\end{aligned}
$$

and

$$
\delta=\kappa_{w 19 / 22} \kappa_{137}-\kappa_{w, 37} \kappa_{1 / 9 / 22} .
$$

For the current study,

$$
\tau_{1}=-\frac{\mu}{2} \ln \left[\begin{array}{l}
T_{s}-T_{19 v / 22 v}+T_{19 / 22}(W, L) \\
\frac{-\Delta T_{19 v / 22 v}}{\left(T_{s}-T_{\cos }\right)\left(1-\epsilon_{19 v / 22 v}\right) \mathscr{J}_{o x \mid 9 / 22}^{2}}
\end{array}\right]
$$


TABLE A1. Model calibration factors $(K)$ for the DMSP $F-8$, $F \cdot 10$, and $F \cdot 1 /$ satellites. Two different values are shown for $\Delta T_{174}$. The first values are used for the $19.35 \mathrm{v} / 37 \mathrm{v} \mathrm{GHz}$ retrievals; those in parentheses are for the $22.235 \mathrm{v} / 37 \mathrm{v} \mathrm{GHz}$ retrievals.

\begin{tabular}{cccc}
\hline Satellite & $\Delta T_{19 \mathrm{v}}$ & $\Delta T_{33 \mathrm{v}}$ & $\Delta T_{37 \mathrm{v}}$ \\
\hline$F .8$ & -2.2 & -2.6 & $1.31(0.95)$ \\
$F \cdot 10$ & -2.2 & -2.6 & $1.2(0.84)$ \\
$F .11$ & -2.8 & -3.0 & $0.93(0.57)$ \\
\hline
\end{tabular}

$$
\tau_{2}=-\frac{\mu}{2} \ln \left[\begin{array}{l}
T_{s}-T_{37 v}-1.5 \\
\frac{+T_{37}(W, L)-\Delta T_{37 v}}{\left(T_{s}-T_{\cos }\right)\left(1-\epsilon_{37 v}\right) \mathscr{J}^{2} x_{37}}
\end{array}\right],
$$

and

$$
T_{\nu}(W, L)=-\Gamma\left[Z_{\nu}^{+}+\left(1-\epsilon_{\mathrm{v}, \nu}\right) Z_{\nu}^{-} \mathfrak{J}_{\nu}\right],
$$

where $\tau_{1}$ is defined for either the $19.35 \mathrm{v}$ or $22.235 \mathrm{v}$ channels, $T_{19 v / 22 v}$ and $T_{37 v}$ are the observed vertical polarization brightness temperatures at 19.35 or 22.235 and at $37 \mathrm{GHz}$ respectively, $\mathscr{J}_{0 \times 19 / 22}$ and $\mathscr{J}_{0 \times 37}$ are the oxygen transmittances, $\kappa_{119 / 22}$ is the liquid water mass absorption coefficient at 19.35 or $22.235 \mathrm{GHz}$ and $\kappa_{w .19 / 22}$ is the water vapor mass coefficient at 19.35 or $22.235 \mathrm{GHz}$, which represents the scaling factor between the total water vapor optical depth and $W$. The factor of -1.5 in (A4) is the offset required for $T_{37 v}$ computed from the simple model to agree with calculations from a more detailed model. The quantities $\Delta T_{19 \mathrm{v}}, \Delta T_{22 \mathrm{v}}$, and $\Delta T_{37 \mathrm{v}}$ account for unmodeled effects, uncertainties in gaseous absorption, and possible sources of bias, including systematic biases in the brightness temperatures and biases in the surface emissivities.

Values of $\Delta T_{19 v}$ and $\Delta T_{22 y}$ for the SSM/I on the DMSP $F-8$ satellite are indicated in Table $\mathrm{A} 1$, and were obtained through comparisons of the water vapor retrievals to radiosonde measurements. Preliminary values for these factors for the instruments on the DMSP $F-10$ and $F-11$ satellites are also given in Table Al, which were determined by intercalibrating $F-8$ measurements of optical depth $\left(\tau_{1}\right.$ and $\left.\tau_{2}\right)$ with measurements from the $F-10$ (coincident overpasses) and $F-I I$ (overpasses within about $15-18 \mathrm{~min}$ ).

The physical variables in (A1) - (A5) are specified as follows. Here, $\Gamma$ is set to a value of $5.8 \mathrm{deg} \mathrm{km}-1$ and $T_{\text {cos }}=2.7 \mathrm{~K}$. Here $H_{w}$ and $H_{l}$ are specified as 2.0 $\mathrm{km}$ and $1.5 \mathrm{~km}$, respectively (note that an accurate value of $H_{l}$ is not essential). The surface skin temperature $\left(T_{s}\right)$ is approximated as the monthly mean sea surface temperature (SST), using the datasets compiled by Reynolds (1988). The water vapor coefficients, $\kappa_{w 19}$ and $\kappa_{w 22}$, are determined to be $2.3 \times 10^{-3}$ $\mathrm{m}^{2} \mathrm{~kg}^{-1}$ and $6.19 \times 10^{-3} \mathrm{~m}^{2} \mathrm{~kg}^{-1}$. The effective cloud temperature, which is used to calculate $\kappa_{119}, \kappa_{122}$, and $\kappa_{137}$ (see, e.g., Greenwald et al. 1993), is estimated as the average of the monthly mean SST and an ISCCPderived 4-year mean (1987-1990) midlevel cloud-top temperature, which was determined for each month of the year. This was done to improve upon the simple assumptions used in the study of Greenwald et al. (1993) and to address the concerns of Liu and Curry (1993) and Lin and Rossow (1994). The oxygen optical depths $\left(\tau_{o x . \nu}\right)$ depend somewhat on the temperature profile. This dependence was parameterized through the surface air temperature $\left(T_{a}\right)$ as $\tau_{o x, \nu}=c_{1, \nu}$ $+c_{2, \nu} T_{a}+c_{3, \nu} T_{a}^{2}+c_{4, \nu} T_{a}^{3}$, where $T_{a}$ is replaced by the monthly mean SST in degrees Celsius. If $T_{a}<0^{\circ} \mathrm{C}$, then set $\tau_{o x, \nu}=c_{1, \nu}$. Table A2 shows the cubic fit coefficients.

Based on the calibration procedure described by Greenwald et al. (1993), $\kappa_{w 37}$ was determined to be $2.04 \times 10^{-3} \mathrm{~m}^{2} \mathrm{~kg}^{-1}$ for the $19 \mathrm{v} / 37 \mathrm{v} \mathrm{GHz}$ water vapor retrievals and $1.93 \times 10^{-3} \mathrm{~m}^{2} \mathrm{~kg}^{-1}$ for the $22 \mathrm{v} / 37 \mathrm{v}$ $\mathrm{GHz}$ water vapor retrievals. Values for $\Delta T_{37 \mathrm{v}}$ are shown in Table A1. Slightly different values of $\kappa_{w, 37}$ and $\Delta T_{37 v}$ were obtained for the different methods since the calibration also accounts for other effects (i.e., unmodeled effects, surface emissivity biases, etc.), which may differ at 19.35 and $22.235 \mathrm{GHz}$.

The emissivity of a smooth ocean surface was computed using the Fresnel formulas and the dielectric constants described by Klein and Swift (1977). For a rough ocean surface the empirical model of Petty (1990) and Petty and Katsaros (1994) was used, where we excluded the emissivity bias corrections derived by Petty (1990).

Retrievals of $W$ and $L$ are obtained by an iterative process. First, initial guesses are found by setting $T_{\nu}(W, L)=0$ in (A5) and then directly computing $W$ and $L$ from (A1) and (A2). The initial guesses require an estimate of the surface wind speed $(u)$, which is used as input into the roughness emissivity model. For this step, we use the wind speed retrieval algorithm described by Goodberlet et al. (1989). To obtain solutions for $W$ and $L$, one simply uses the initial guesses

TABLE A2. Cubic fit coefficients for oxygen optical depths $\left(\tau_{u x}\right)$ at $19.35,22.235$, and $37 \mathrm{GHz}$.

\begin{tabular}{llcll}
\hline \hline Frequency & $c_{1}$ & $c_{2}$ & $c_{3}$ & $c_{4}$ \\
\hline 19.35 & 0.0134 & $3.86 \times 10^{-5}$ & $-4.74 \times 10^{-6}$ & $6.12 \times 10^{-8}$ \\
22.235 & 0.0155 & $4.46 \times 10^{-5}$ & $-5.57 \times 10^{-5}$ & $7.33 \times 10^{-8}$ \\
37 & 0.0453 & $1.33 \times 10^{-4}$ & $-1.67 \times 10^{-5}$ & $2.26 \times 10^{-7}$ \\
\hline
\end{tabular}


of $W$ and $L$ to compute $T_{\nu}(W, L)$ and a new wind speed from the following preliminary expression (G. Petty 1993, personal communication)

$$
u^{\prime}=u-2.130+0.220 W-4.008 \times 10^{-3} W^{2},
$$

which corrects for biases in the Goodberlet et al. algorithm that are known to exist for low and, especially, high water vapor. This process is repeated until the desired precision is achieved.

For retrievals of $W$, the $22 \mathrm{v} / 37 \mathrm{v}$ method gives superior results for low to moderately high water vapor. At the highest values of $W$ (greater than about 55-60 $\mathrm{kg} \mathrm{m}^{-2}$ ), the retrievals begin to underestimate the actual water vapor as a result of the reduced sensitivity of the $22.235 \mathrm{GHz}$ channel to changes in water vapor. Consequently, a weighted combination of the $19 \mathrm{v} / 37 \mathrm{v}$ $\left(W_{19}\right)$ and $22 \mathrm{v} / 37 \mathrm{v} \mathrm{GHz}\left(W_{22}\right)$ retrievals is used. If $W_{22}$ is greater than $53.4 \mathrm{~kg} \mathrm{~m}^{-2}$, the following weighting is applied:

$$
W=W_{22}+1.75-0.263 W_{19}+4.31 \times 10^{-3} W i_{19}^{2} .
$$

This equation was determined from a least-squares fit of the retrievals of $W_{22}$ and $W_{19}$. When compared to radiosonde measurements from the study of Greenwald et al. (1993), the present method provides substantial improvements over the $19 \mathrm{v} / 37 \mathrm{v}$ method of Greenwald et al. The rms differences are reduced from 1.9 to 1.4 $\mathrm{kg} \mathrm{m}^{-2}$ for the International Cirrus Experiment data and from 5.9 to $4.6 \mathrm{~kg} \mathrm{~m}^{-2}$ for the Tropical Cyclone Motion experiment data.

\section{REFERENCES}

Ackerman, S. A., and T. Inoue, 1994: Radiation energy budget studies using collocated AVHRR and ERBE observations. J. Appl. Meteor., 33, 370-378.

—, R. A. Frey, and W. L. Smith, 1992: Radiation budget studies using collocated observations from AVHRR, HIRS/2 and ERBE instruments. J. Grophys. Res., 97, 11 513-11 525.

Albrecht, B. A., D. A. Randall, and S. Nicholls, 1988: Observations of marine stratocumulus clouds during FIRE. Bull. Amer. Meteor. Soc., 69, 618-626.

Barkstrom, B. R., 1984: The Earth Radiation Budget Experiment (ERBE). Bull. Amer. Meteor. Soc., 65, 1170-1185.

Bauer, P., and P. Schluessel, 1993: Rainfall, total water, ice water, and water vapor over sea from polarized microwave simulations and Special Sensor Microwave/Imager data. J. Geophys. Res., 98, 20 737-20759.

Betts, A. K., and Harshvardhan, 1987: Thermodynamic constraint on the cloud liquid water feedback in climate models. J. Geophys. Res., 92, 8483-8485.

Cahalan, R. F., W. Ridgway, W. J. Wiscombe, T. L. Bell, and J. B. Snider, 1994: The albedo of fractal stratocumulus clouds. $J$. Atmos. Sci., 51, 2434-2455.

Charlock, T. P., 1982: Cloud optical feedback and climate stability in a radiative-convective model. Tellus, 34, 245-254.

Dlhopolsky, R., and R. D. Cess, 1993: Improved angular directional models for clear sky ocean derived from earth radiation budget satellite shortwave radiances. J. Geophys. Res., 98, $16713-$ 16721 .

Goodberlet, M. A., C. T. Swift, and J. C. Wilkerson, 1989: Remote sensing of ocean surface winds with the Special Sensor Microwave/Imager. J. Geophys. Res., 94, $14547-14555$.
Greenwald. T. J., G. L. Stephens. T. H. Vonder Haar and D. L. Jackson, 1993: A physical retrieval of cloud liquid water over the global oceans using Special Sensor Microwave/Imager (SSM/ I) observations. J. Geophys. Res., 98, $18471-18488$.

Han, Q., W. R. Rossow, and A. A. Lacis, 1994: Near-global survey of effective droplet radii in liquid water clouds using ISCCP data. J. Climate, 7, 465- 497.

Herman, G. F., and J. A. Curry, 1984: Observational and theoretical studies of solar radiation in arctic stratus clouds. J. Climate Appl. Meteor., 23, 5-24.

Hollinger, J. P., J. L. Pierce, and G. A. Poe, 1990: SSM/I instrument evaluation. IEEE Trans. Geosci. Remote Sens., GE-28. 781791

Jackson, D. L., and G. L. Stephens. 1995: A study of SSM/I-derived columnar water vapor over the global oceans. J. Climate, 8, 2025-2038.

Jones, A. S., and T. H. Vonder Haar, 1990: Passive microwave remote sensing of cloud liquid water over land regions. J. Geophys. Res., 95, $16673-16683$.

King, M. D., and Harshvardhan, 1986: Comparative accuracy of selected multiple scattering approximations. J. Atmos. Sci., 43, 784-801.

Klein, L. A., and C. T. Swift, 1977: An improved model for the dielectric constant of sea water at microwave frequencies. IEEE Trans. Antennas Propag., AP-25, 104-111.

Klein, S. A., and D. L. Harmann. 1993: The seasonal cycle of low stratiform clouds. J. Climate, 6, 1587-1606.

Kopia. L. P., 1986: Earth Radiation Budget Experiment scanner instrument. Rev. Geophys., 24, 400-406.

Liebe, H. J., G. A. Hufford, and M. G. Cotton, 1993: Propagarion modeling of moist air and suspended water/ice particles at frequencies below $1000 \mathrm{GHz}$. Atmospheric propagation effects through natural and man-made obscurants for visible to $\mathrm{MM}$ wave radiation, AGARD Conference Proceedings, No. 542, 3.1-3.10.

Lin, B., and W. B. Rossow, 1994: Observations of cloud liquid water path over oceans: Optical and microwave remote sensing methods. J. Geophys. Res., 99, 20907-20927.

Liu, G., and J. A. Curry, 1993: Determination of characteristic features of cloud liquid water from satellite measurements. $J$. Geophys. Res., 98, 5069-5092.

McClatchey, R. A., R. W. Fenn, J. E. Selby, F. E. Voltz. and J. S. Garing, 1972: Optical properties of the atmosphere. 3rd ed. AFCRL-72-0497, $108 \mathrm{pp}$

Paltridge, G. W., 1980: Cloud-radiation feedback to climate. Quart. J. Roy. Meteor. Soc., 106, 895-899.

Petry, G. W., 1990: On the response of the Special Sensor Microwave/Imager to the marine environment - Implications for atmospheric parameter retrievals. Ph.D. dissertation, University of Washington, $291 \mathrm{pp}$.

- and K. B. Katsaros, 1992: The response of the SSM/I to the marine environment. Part I: An analytic model for the atmospheric component of observed brightness temperatures. $J$. Atmos. Oceanic Technol., 9, 746-761.

, and $-1994:$ The response of the SSM/I to the marine environment. Part II: A parameterization of the effect of the sea surface slope distribution on emission and reflection. J. Atmos. Oceanic Technol., 11, 617-628.

Poe, G. A., and R. W. Conway, 1990: A study of the geolocation errors of the Special Sensor Microwave/Imager (SSM/I). IEEE Trans. Geosci. Remote Sens., 28, 791-799.

Reynolds, R. W., 1988: A real-time global sea surface temperature analysis. J. Climate, $1,75-86$.

Rossow, W. B., and R. A. Schiffer, 1991: ISCCP cloud data products. Bull. Amer. Meteor. Soc., 72, 2-20.

Slingo, A., S. Nicholls, and J. Schmetz, 1982: Aircraft observations of marine stratocumulus during JASIN. Quart. J. Roy. Meteor. Soc., 108, 833-865.

Somerville, R. C. J., and L. A. Remer, 1984: Cloud optical thickness feedbacks in the $\mathrm{CO}_{2}$ climate problem. J. Geophys. Res., 89, 9668-9672. 
Spencer, R. W., 1993: Global oceanic precipitation from the MSU during 1979-91 and comparisons to other climatologies. J. Climate, 6, 1301-1326.

Stackhouse, P. W., Jr., and G. L. Stephens, 1991: A theoretical and observational study of the radiative properties of cirrus: Results from FIRE 1986. J. Atmos. Sci., 48, 2044-2059.

Stamnes, K., and S.-C. Tsay, 1990: Optimum spectral resolution for computing atmospheric heating and photodissociation rates. Planet. Space Sci., 38, 807-820.

Stephens, C. L., and C. M. R. Platt, 1987: Aircraft observations of the radiative and microphysical properties of stratocumulus and cumulus cloud fields. J. Climate Appl. Meteor., 26, 1243-1269. and T. J. Greenwald, 1991: The earth's radiation budget and its relation to atmospheric hydrology. Part 2: Observations of cloud effects. J. Geophys. Res., 96, $15325-15340$.

Suttles, J. T., B. A. Wielicki, and S. Vemury, 1992: Top-of-atmosphere radiative fluxes: Validation of ERBE scanner inversion algorithm using Nimbus-7 ERB data. J. Appl. Meteor., 31, 784796.

Taylor, K. E., and S. J. Ghan, 1992: An analysis of cloud liquid water feedback and global climate sensitivity in a general circulation model. J. Climate, 5, 907-919.
Tjemkes, S. A., G. L. Stephens, and D. L. Jackson, 1991: Spaceborne observation of columnar water vapor: SSMI observations and algorithm. J. Geophys. Res., 96, $10941-10954$.

Tselioudis, G., W. B. Rossow, and D. Rind, 1992: Global patterns of cloud optical thickness variation with temperature. J. Climate. 5, 1484-1495.

Twomey, S., 1991: Aerosols, clouds and radiation. Atmos. Environ., 25A, 2435-2442.

Wallace, J. M., G.-H. Lim, and M. L. Blackmon, 1988: Relationship between cyclone tracks, anticyclone tracks and baroclinic waveguides. J. Atmos. Sci., 45, 439-462.

Wentz, F. J., 1983: A model function for ocean microwave brightness temperatures. J. Geophys. Res., 88, 1892-1908. 1991: User's Manual-SSM/I Antenna Temperature Tapes. Remote Sensing Systems, $70 \mathrm{pp}$.

Westwater, E. R., 1978: The accuracy of water vapor and cloud liquid determination by dual-frequency ground-based microwave radiometry. Radio Sci., 13, 677-685.

Wielicki, B. A., R. D. Cess, M. D. King, D. A. Randall, and E. F. Harrison, 1995: Mission to planet earth: Role of clouds and radiation in climate. Bull. Amer. Meteor. Soc., 76, $2125-$ 2153. 